\title{
Practitioner Review: Borderline personality disorder in adolescence: recent conceptualization, intervention, and implications for clinical practice
}

\author{
Carla Sharp ${ }^{1}$ and Peter Fonagy ${ }^{2}$ \\ ${ }^{1}$ Department of Psychology, University of Houston, and The Menninger Clinic, Houston, Texas, USA; \\ ${ }^{2}$ Research Department of Clinical, Educational and Health Psychology, University College London, and \\ The Anna Freud Centre, London, UK
}

\begin{abstract}
Background: The past decade has seen an unprecedented increase in research activity on personality disorders (PDs) in adolescents. The increase in research activity, in addition to major nosological systems legitimizing the diagnosis of borderline personality disorder (BPD) in adolescents, highlights the need to communicate new research on adolescent personality problems to practitioners. Scope: In this review, we provide up-to-date information on the phenomenology, prevalence, associated clinical problems, etiology, and intervention for BPD in adolescents. Our aim was to provide a clinically useful practitioner review and to dispel long-held myths about the validity, diagnostic utility, and treatability of PDs in adolescents. Findings and conclusion: Alongside providing up-to-date information on the phenomenology, prevalence, and etiology, we also report on associated clinical problems and interventions for adolescent BPD. It is only through early active assessment and identification of youngsters with these problems that a lifetime of personal suffering and health system burden can be reduced or altogether avoided. A variety of evidencebased approaches are now available to treat BPD and related clinical problems in young people. Future research should focus on establishing optimal precision in the diagnostic processes in different treatment settings. Keywords: Borderline personality disorder; adolescence; intervention; etiology; assessment.
\end{abstract}

\section{Introduction: personality disorder in adolescence}

In 2013, the fifth edition of the Diagnostic and Statistical Manual of Mental Disorders (DSM-5) was released in the midst of significant controversy over the question whether personality disorders (PDs) should be defined as categorical entities or combinations of extreme personality dimensions. The DSM-5 now contains two parallel classification systems for PD. In Section II, the 10 DSM-IV categorical diagnoses with polythetic criteria were retained, but in Section III (Emerging Measures and Models), a dimensional trait-based approach is described. A shift toward a dimensional trait-based approach is also represented in proposals for the International Classification of Diseases 11th Revision (ICD-11) Tyrer, 2014; Tyrer et al., 2011). Of the 10 DSM-5 Section II PDs, three have been the subject of consistent interest in youth (defined as the period between childhood and adult age): (a) schizotypal PD (SPD), (b) antisocial PD (ASPD) (and psychopathy), and (c) borderline PD (BPD). Both adolescent SPD and ASPD (psychopathy) touch on massive literatures (on psychosis and antisocial behavior, respectively) that are separate from the literature on PD, and no adequate review of these could be provided within the constraints of a practitioner review. We focus this review on BPD both for this reason and

Conflicts of interest statement: No conflicts declared. also because there has been a fivefold increase in empirical studies examining BPD in adolescent populations over the past 10 years (Sharp \& Tackett, 2014), which is not the case for any other DSMdefined PD. Second, analogizing from the construct of intelligence, which has long understood the structure of mental ability to comprise general (i.e. 'g') and specific (i.e. 's') skills, BPD has been shown to be the 'g-factor' of personality pathology (Sharp et al., 2015) - that is, of all the PDs, BPD appears to capture the core of personality pathology or may be most representative of all PDs ${ }^{1}$.

We begin this review with the diagnosis and clinical features of adolescent BPD. We discuss the phenomenology of adolescent BPD to include diagnostic criteria (and a case vignette for illustrative purposes), the underlying factor structure of adolescent BPD, comorbidity, and associated clinical features. Next, we discuss prevalence, assessment, etiology, course and prognosis, and treatment approaches. We conclude with suggestions for future research.

\section{Borderline personality disorder The phenomenology of adolescent BPD}

Diagnostic criteria. Despite long-standing general consensus (as early as the DSM-II; American Psychiatric Association, 1968) that BPD symptoms usually first become apparent in adolescence (Chanen \& 
Kaess, 2012; Shiner, 2009), the majority (63\%) of British psychiatrists considered the diagnosis of adolescent PD to be invalid when surveyed in 2009 (Griffiths, 2011), and many clinicians remain uncomfortable diagnosing PD in children and adolescents (Laurenssen, Hutsebaut, Feenstra, Van Busschbach, \& Luyten, 2013). Explanations for this reluctance have included concerns about stigma (Kernberg, Weiner, \& Bandenstein, 2000) and the notion that identity formation was incomplete in this age group (Shapiro, 1990). Others have emphasized the problem of distinguishing borderline features from the normal developmental trajectory of adolescence (Meijer, Goedhart, \& Treffers, 1998; Miller, Muehlenkamp, \& Jacobson, 2008). Indeed, there have been anecdotal suggestions that all adolescents are 'a bit borderline' given the increase in emotional lability during the adolescent period (Paris, 2014). While it is true that boys and girls undergo dramatic bodily and socioemotional changes during adolescence, (Fossati, 2014; Nelson, Leibenluft, McClure, \& Pine, 2005), the notion of 'adolescent turmoil' ('storm and stress') has received only limited support from developmental research (Cicchetti \& Rogosch, 2002). However, in a recent large multiwave epidemiological study of the prognosis of common mental disorders of adolescence (Patton et al., 2014), an increased likelihood of poor long-term outcome in those whose problems persisted through adolescence was reported. The study confirms that psychopathology persisting over a year should not be written off as a transient phenomenon, and this is likely to apply to BPD (Paris, 2014).

Accordingly, there is now consensus that BPD constitutes a valid and reliable diagnosis in adolescence (Chanen \& McCutcheon, 2008; Miller et al., 2008; Sharp \& Romero, 2007). Evidence has been provided for the longitudinal continuity of BPD (Bornovalova, Hicks, Iacono, \& McGue, 2009; Chanen et al., 2004; Cohen et al., 2008), albeit only at the trait level. This finding mirrors research in adult BPD, which has shown categorical diagnoses to be highly unstable (Zanarini, Frankenburg, Reich, \& Fitzmaurice, 2012). A genetic basis (Distel et al., 2008; Kendler, Prescott, Myers, \& Neale, 2003; Torgersen et al., 2008), overlap in the latent variables underlying symptoms (Bradley, Zittel Conklin, \& Westen, 2005; Gratz et al., 2009) and the risk factors (Carlson, Egeland, \& Sroufe, 2009; Rogosch \& Cicchetti, 2005) for BPD in adolescents and in adults, and evidence for marked separation of the course and outcome of adolescent BPD and other disorders (Chanen, Jovev, \& Jackson, 2007) provide further support for the validity of adolescent BPD. Importantly, treatment specifically developed to address the problems associated with adolescent BPD, such as mentalization-based treatment (MBT; Rossouw \& Fonagy, 2012) and dialectical behavior therapy (DBT; Miller, Carnesale, \& Courtney, 2014), as well as early intervention (Chanen, McCutcheon, Jovev,
Jackson, \& McGorry, 2007), has been shown to be beneficial, thereby further bolstering the validity of the disorder in adolescence.

Section II of the DSM-5 states that the diagnosis of BPD may be applied to children or adolescents when 'the individual's particular maladaptive personality traits appear to be pervasive, persistent, and unlikely to be limited to a particular developmental stage or another mental disorder' (American Psychiatric Association, 2013, p. 647). In contrast to the 2 years necessary for an adult PD to be diagnosed, only 1 year is necessary for child/adolescent PD. DSM-5 Section II criteria include abandonment fears, unstable and intense interpersonal relationships, identity disturbance, impulsivity, suicidal behaviors, affective instability, chronic feelings of emptiness, inappropriate intense anger and transient, stress-related paranoid ideation, or severe dissociative symptoms. These symptoms can be clearly distinguished from typical adolescence by their severity, pervasiveness, and time course, and from pure internalizing and externalizing disorders by the confluence of both internalizing and externalizing symptoms within BPD. The typical symptoms of adolescent BPD are illustrated in the case vignette shown in Box 1.

In contrast to Section II, DSM-5 Section III requires clinicians to consider two sets of criteria (Criteria A and $\mathrm{B}$ ) in the assessment of BPD. Criterion A requires judgment of severity of problems in identity, self-direction, empathy, and intimacy. Criterion B requires the presence of four or more of the following seven pathological personality traits: emotional lability, anxiousness, separation insecurity, depressivity, impulsivity, risk-taking, and hostility; of which at least one must be impulsivity, risk-taking, or hostility. The case vignette above clearly demonstrates problems in intimacy and self-direction, in addition to problems in emotional lability, separation insecurity, anxiousness, impulsivity, risk-taking, and hostility.

While the ICD-1 1 and national treatment guidelines for the U.K. (National Institute for Health and Clinical Excellence, 2009) and Australia (National Health and Medical Research Council, 2013) also now 'legitimize' the diagnosis of BPD in adolescence, the DSM-5 retains the history of conservatism about giving the diagnosis to children and adolescents, urging clinicians to restrict the diagnosis to 'relatively unusual instances' (American Psychiatric Association, 2013, p. 647). The fear of stigma may be appropriate; equally, we should not collude with it if effective therapies could be made available following appropriate diagnosis (see later section on Intervention). Importantly, for those clinicians who prefer a more dimensional trait-based approach to classification and diagnosis, the DSM-5 Section III criteria, in addition to several well-validated trait measures of BPD (see later section on Assessment), allow for an alternative noncategorically based diagnostic procedure. 
Box 1 Case vignette for typical symptoms of adolescent BPD

Sarah is a 15-year-old adolescent who was admitted to an inpatient unit after she made a serious threat to kill herself. Sarah's parents got divorced when she was 4 years old and she has been spending alternate weekends with her father. On the day she was admitted to hospital, Sarah's father brought her to the meeting point (a park) where he was going to drop off Sarah to be picked up by her mother. When he began to leave, Sarah clung to him and started to cry. Sarah has had a tendency in the past to engage in dramatic displays to stop her parents or good friends from leaving her. This time, Sarah told her father that living with her mother had become unbearable and that if he did not stay with her she would kill herself. During the past 2 years Sarah has often threatened to kill herself. Her father tried to calm her down but she shouted that he was not hearing her and she pulled up her skirt to reveal significant cuts and burns on her thighs. Her father was shocked; since childhood, Sarah had always been highly emotional and reactive. Recently, her father had become concerned about Sarah's alcohol intake and the fact that she was caught shoplifting a few times, but her father had not been aware of any self-harm. Sarah disclosed that she has been cutting and burning herself for at least 2 years. By this time Sarah was sobbing angrily and accusing her father of never being there for her and choosing a life with his new family instead of her. When her father tried to hold her to comfort her, she punched him in the face and started running away. When a car nearly ran her over she collapsed and her father was able to catch up with her to take her to the hospital. On admission, Sarah appeared completely calm and said that she felt separated from her body - a feeling which she said she often has when she becomes stressed. She kept scratching herself. She did not want her mother to come to the hospital.

Factor structure of BPD diagnostic criteria. A major issue for the validity and phenomenology of BPD is whether DSM criteria define a single diagnostic entity. For a disorder to be valid, its criterion set must constitute a coherent combination of traits and symptoms that 'hang together' (Robins \& Guze, 1970), as would be evidenced by a single common factor adequately accounting for covariation among the criteria. Six published studies have examined the factor structure of the DSM criteria for BPD using youth samples (Michonski, 2014). Four of those reported an acceptably fitting unidimensional solution (Chabrol et al., 2002; Leung \& Leung, 2009;
Sharp, Ha, Michonski, Venta, \& Carbone, 2012), and the remaining two studies did not directly test the adequacy of a unidimensional model (Becker, McGlashan, \& Grilo, 2006; Speranza et al., 2012). These studies vary in terms of their methodological strengths. For instance, Chabrol et al.'s (2002) sample consisted of only 60 adolescents, and the sample in the study of Sharp et al. (2012) consisted of a predominantly middle- and upper-class families. However, in summary, where multidimensional models showed superior fit in the above studies, high correlations between factors were shown, in some cases nearing unity (Sanislow et al., 2002). Thus, a unidimensional model appears to offer the most parsimonious conceptualization (Michonski, 2014). It should be noted, however, that the true test for the unidimensionality of BPD would be in studies where PDs are factor analyzed simultaneously. If BPD retains its unidimensionality under those circumstances, its validity as a discrete disorder is substantiated. While such studies are yet to be undertaken in adolescent samples, evidence from studies of adults with PD is mixed, with most studies failing to support a unidimensional factor structure for BPD (Sharp et al., 2015; Sheets \& Craighead, 2007).

Studies that aim to determine borderline symptoms that are most predictive of adolescent BPD are sparse. Early studies reported that the most stable symptoms in adolescents were chronic feelings of emptiness and inappropriate, intense anger (see the case vignette in Box 1 for an example of inappropriate, intense anger; Garnet, Levy, Mattanah, Edell, \& McGlashan, 1994). Five later studies identified symptoms of identity disturbance, affective instability, and inappropriate, intense anger as having the greatest predictive power for BPD in adolescents (Becker, Grilo, Edell, \& McGlashan, 2002; McManus, Lerner, Robbins, \& Barbour, 1984; Meijer et al., 1998; Pinto, Grapentine, Francis, \& Picariello, 1996; Westen, Betan, \& Defife, 2011). Using Item Response Theory analyses, Michonski, Sharp, Steinberg, \& Zanarini (2013b) demonstrated that paranoid ideation (in boys) and identity disturbance (in girls) were the most discriminating symptoms of BPD in adolescents. The positive predictive power of identity disturbance, affective instability, and inappropriate, intense anger is almost identical to that identified in the adult BPD literature (Becker et al., 2002; Blais, Hilsenroth, \& Fowler, 1999), suggesting that key symptom criteria are valid across age groups. Based on this literature, Fossati (2014) summarized the best nominated symptom identifiers for BPD in adolescence, replicated here in Table 1. Table 1 also contains early childhood predictors of BPD. However, these predictors lack specificity for BPD and evidence is limited to justify the use of these childhood predictors as the sole basis for prevention or early intervention. We also caution against overreliance on the core diagnostic features summarized in Table 1. These features have been distilled from 
Table 1 Best nominated symptom identifiers for borderline personality disorder (BPD) in adolescence and early childhood markers of vulnerability (adapted from Fossati, 2014)

Borderline personality disorder in adolescence

Core diagnostic features

Identity disturbance (particularly for girls)

Inappropriate, intense anger

Paranoid ideation (boys)

Chronic feelings of emptiness

(Deliberate self-harm, dissociation proneness)

Childhood markers

Childhood disorders

Attention-deficit/hyperactivity disorder

Oppositional defiant disorder

Childhood problem behavior

Controlling and coercive behaviors toward attachment figures

Poorly defined sense of self

Hostile, distrustful view of the world

Relational aggression

Intense outbursts of anger

Affective instability

Note. No single diagnostic element is suggestive of a BPD diagnosis in adolescence; rather, a pattern of 2-3 diagnostic criteria may be suggestive of BPD in adolescence. Diagnostic criteria between brackets indicate BPD characteristics that frequently occur in the clinical presentation of BPD in adolescence, although they lack diagnostic specificity. The above symptoms are based on sparse literature that needs replication.

prior longitudinal studies of BPD in children and adolescents, which were not without methodological limitations. For instance, the Children in the Community study (CIC; Cohen, 2008), while of great importance as the first longitudinal communitybased study of borderline symptoms, made use of unvalidated measures of BPD. Only through new longitudinal follow-up studies using appropriate measures can the best nominated core symptom identifiers be determined.

Comorbidity. As evident in the case vignette, adolescents with BPD struggle not only with symptoms specific to BPD but also with symptoms of both internalizing and externalizing disorder. Indeed, adult BPD demonstrates high comorbidity with both internalizing and externalizing disorders (Grant et al., 2008; Lenzenweger, Lane, Loranger, \& Kessler, 2007; McGlashan et al., 2000; Oldham \& DeMasi, 1995; Skodol et al., 2002; Widiger \& Trull, 1993; Zanarini et al., 1998; Zimmerman \& Mattia, 1999). Comorbidity studies in adolescents demonstrate that adult patterns are mirrored, ranging from $50 \%$ in the CIC (Cohen, 2008) to $86 \%$ in a clinical sample (Speranza et al., 2011). Similar rates of comorbidity have been reported in other studies of adolescent BPD (Kaess, von Ceumern-Lindenstjerna, et al., 2013). Chanen, Jovev, et al. (2007) demonstrated significantly higher rates of comorbidity in borderline adolescents compared to adolescents with either no PD or no disorder. Recently, Ha, Balderas, Zanarini, Oldham, \& Sharp, 2014 reported rates of $70.6 \%$ for comorbid mood disorders in adolescent inpatients with BPD (vs. $39.2 \%$ in nonBPD psychiatric controls), $67.3 \%$ for anxiety disorders (vs. $45.5 \%$ ), and $60.2 \%$ for externalizing disorders (vs. 34.4\%). In this, the largest study of adolescent inpatients, adolescents with BPD also showed significantly higher scores on dimensional measures of internalizing and externalizing psychopathology compared to psychiatric controls, and they showed significantly higher likelihood of meeting criteria for complex comorbidity as defined by Zanarini et al. (1998) as having any mood or anxiety disorder plus a disorder of impulsivity.

High rates of comorbidity suggest that underlying structures may account for observed comorbidity (covariance) among disorders (Eaton et al., 2011). Historically, BPD was considered to occupy the area between the neuroses (e.g. depression and anxiety) and psychoses (e.g. schizophrenia; Deutsch, 1942; Hoch \& Polatin, 1949). Recent studies (James \& Taylor, 2008) found that BPD served as a multidimensional indicator of both the externalizing dimension and the anxious-misery (distress) subfactor of the internalizing dimension across both genders. Indicator in this sense refers to the fact that the BPD factor in these studies statistically loaded on to disorders characterized as both internalizing and externalizing. This finding has been replicated in adolescents (C. Sharp, et al., under review). Taken together, this evidence suggests that BPD is neither an internalizing disorder (Akiskal et al., 1985), nor is it a female expression of antisocial personality disorder (Paris, 1997), but it likely represents a confluence of internalizing and externalizing problems; that is, the construct of BPD contains characteristics of both internalizing and externalizing disorders, while still retaining its independence as a separate disorder. This finding is also consistent with the findings of Chanen, Jovev, et al. (2007) that BPD has explanatory value over and above other traditional Axis I disorders as well as other PDs in predicting current psychosocial functioning.

Associated clinical features. As is often the case when making differential diagnoses in psychiatry, it is not always easy for clinicians to distinguish BPD 
from other traditional Axis I disorders in adolescence, or indeed behaviors that are commonly the subject of adolescent experimentation, but often remit by young adulthood. These behaviors include, for instance, self-harm and substance abuse (Copeland, Shanahan, Costello, \& Angold, 2009; Moran et al., 2012; Paris, 2014). On the other hand, BPD features have been shown to be the best predictor of continued engagement in self-harm through young adulthood (Glenn \& Klonsky, 2011; Wilcox et al., 2012) and recurrent suicide attempts 6 months after hospitalization (Yen et al., 2013). The overall lifetime suicide rate for BPD in adulthood is estimated at $8 \%$ $10 \%$ (Oldham, 2006). Persistent self-harm and suicidal behavior into adulthood is therefore a potential key feature of BPD when attempting to distinguish it from other typical adolescent disorders. However, clinicians cannot wait and see whether these behaviors persist before making a diagnosis - a topic we return to in later sections of the paper.

Other associated features that may further exacerbate the clinical picture of BPD are high risktaking due to general impulsivity and difficulties in dealing with stressful or negative affect (see case vignette for examples). For instance, adolescents with BPD engage in higher rates of sexual risktaking (multiple partners and unprotected sex), which naturally puts them at risk for sexually transmitted diseases (Chanen, Jovev, et al., 2007). In addition, adolescents with BPD show significant impairment in both social functioning and academic performance. Longitudinal studies have shown that these functional impairments persist from adolescence through adulthood despite instability in symptoms (Crawford et al., 2008; Gunderson et al., 2011; Winograd, Cohen, \& Chen, 2008; Zanarini, Frankenburg, Hennen, Reich, \& Silk, 2006).

\section{Prevalence}

In adults, BPD occurs in approximately 1\%-3\% of the general population (Leichsenring, Leibing, Kruse, New, \& Leweke, 2011; Lenzenweger, 2008). While few population-based studies of BPD exist for children and adolescents, early studies reported high rates of BPD in community studies, with values ranging from $11 \%$ in the CIC Study (Bernstein et al., 1993) to $26.7 \%$ (Chabrol et al., 2002). Two recent reports estimated prevalence using different scoring algorithms in a large birth cohort of 6,330 British children 11 years of age (the Avon Longitudinal Study of Parents and Children; ALSPAC study) and found a prevalence of $3.27 \%$ (Zanarini et al., 2011) and of $0.06 \%$ (Michonski, Sharp, Steinberg, \& Zanarini, 2013a), respectively. Other reports have estimated point prevalence for adolescents in the community at around $1 \%$ in the United States (Johnson, Cohen, Kasen, Skodol, \& Oldham, 2008; Lewinsohn, Rohde, Seeley, \& Klein, 1997) and 2\% in China (Leung \& Leung, 2009), and cumulative prevalence at 3\% (Johnson et al., 2008). The picture in clinical populations is more alarming, with rates reported at $11 \%$ in outpatients (Chanen et al., 2004), $33 \%$ (Ha et al., 2014), and $43 \%-49 \%$ of inpatients (Levy et al., 1999).

\section{Onset, stability, and course}

Onset. Borderline personality disorder is currently mostly conceptualized as a developmental disorder with onset in adolescence (Chanen \& Kaess, 2012). Zanarini, Frankenburg, Khera, and Bleichmar (2001) found the mean of first clinical presentation to be age 18 , with a standard deviation of 5-6 years, suggesting age of onset around age 13. Adolescence appears to be a particularly vulnerable period for the development of BPD. Critical developmental tasks of adolescence call for capacities that are salient to the symptom profile of BPD, such as the creation of an independent social network of stable friendships and developing romantic relationships while not neglecting maintaining closeness to family members and honing the capacities required for education and work tasks (Allen et al., 2006; Roisman, Masten, Coatsworth, \& Tellegen, 2004). Indeed, the symptom profile of BPD is highly interpersonal, as also exemplified by the case vignette described earlier, with two DSM criteria explicitly covering problems in interpersonal relationships: Criteria 1 (frantic efforts to avoid real or imagined abandonment) and 2 (a pattern of unstable and intense interpersonal relationships characterized by alternating between extremes of idealization and devaluations). Moreover, in the discussion of diagnostic features associated with each DSM criterion (American Psychiatric Association, 2000, p. 707) the interpersonal nature of most other criteria is clearly evident. For example, Criterion 3 describes how identity disturbance manifests itself most often in situations in which an individual feels a lack of meaningful relationships, nurturing, and support. The impulsivity criterion (Criterion 4) includes unsafe sex and outbursts of anger in the context of relationships. Incidents of self-harm/suicide attempts (Criterion 5) are described as being often precipitated by threats of separation or rejections. Reactivity of mood or affective instability (Criterion 6) is said to often reflect the individual's extreme reactivity to interpersonal stresses, and Criterion 8 (anger) is described as often elicited when a caregiver or lover is seen as neglectful, withholding, uncaring, or abandoning.

The dramatic social-emotional developmental changes associated with adolescence coincide with significant functional and structural brain changes, most notably amygdala hyperactivity (Hare et al., 2008; Monk et al., 2003). Specifically, Monk et al. (2003) showed that the emotional content of social stimuli appeared to drive activation more strongly in the amygdala in adolescents than in adults. In other words, social-emotional developmental tasks 
become salient at exactly the same time adolescents become more strongly motivated by emotional content. Following a developmental psychopathology approach to the development of BPD (see also Figure 1), we propose that a range of normative developmental changes during adolescence (e.g. brain maturation and expanding social networks) may interact with predisposing factors such as early attachment difficulties (Sharp \& Fonagy, 2008) or proximal precipitating factors such as social rejection experiences (Dixon-Gordon, Chapman, Lovasz, \& Walters, 2011) to increase risk of adolescent-onset BPD. As for most child and adolescent psychiatric disorders, early onset is associated with greater severity and a poorer lifetime course (Chanen, McCutcheon, et al., 2007).

Stability and course. The categorical stability of BPD, as discussed earlier, is modest in both adolescents and adults (Chanen et al., 2004; Skodol et al., 2005; Zanarini et al., 2011). Dimensional stability demonstrated moderate stability (Bornovalova et al., 2009; Chanen et al., 2004; Cohen et al., 2008). On average, BPD symptoms appear in adolescence, peak in early adulthood, and then decline (Arens et al., 2013; Chanen \& Kaess, 2012). The balance of evidence suggests that while impulsive- type symptoms do reduce over time, affective-type symptoms, which include negative affect and feelings of emptiness, are more likely to persist (Meares, Gerull, Stevenson, \& Korner, 2011). However, some individuals do not experience an agerelated decline. For instance, in the CIC study, one fifth of the sample of youth showed an increase in PD symptoms over the decade from mid-adolescence to early adulthood (Cohen, Crawford, Johnson, \& Kasen, 2005). Moreover, remission from a categorical diagnosis of BPD does not imply that remitted patients are healthy. As with adults, poor functional outcomes persist for years in individuals who showed borderline features in adolescence, including increased risk for substance use and mood disorders, interpersonal problems, poorer quality of life, and higher levels of general distress (Crawford et al., 2008; Winograd et al., 2008), service utilization (Cailhol et al., 2013), and increased rates of pain, physical illness, and mortality over time (Chen et al., 2009).

Although speculative at this point, and consistent with a developmental psychopathology framework, evidence is beginning to emerge in support of a heterotypic developmental course for BPD - that is, coherence in the underlying organization or meaning of behaviors over time (as opposed to homotypic

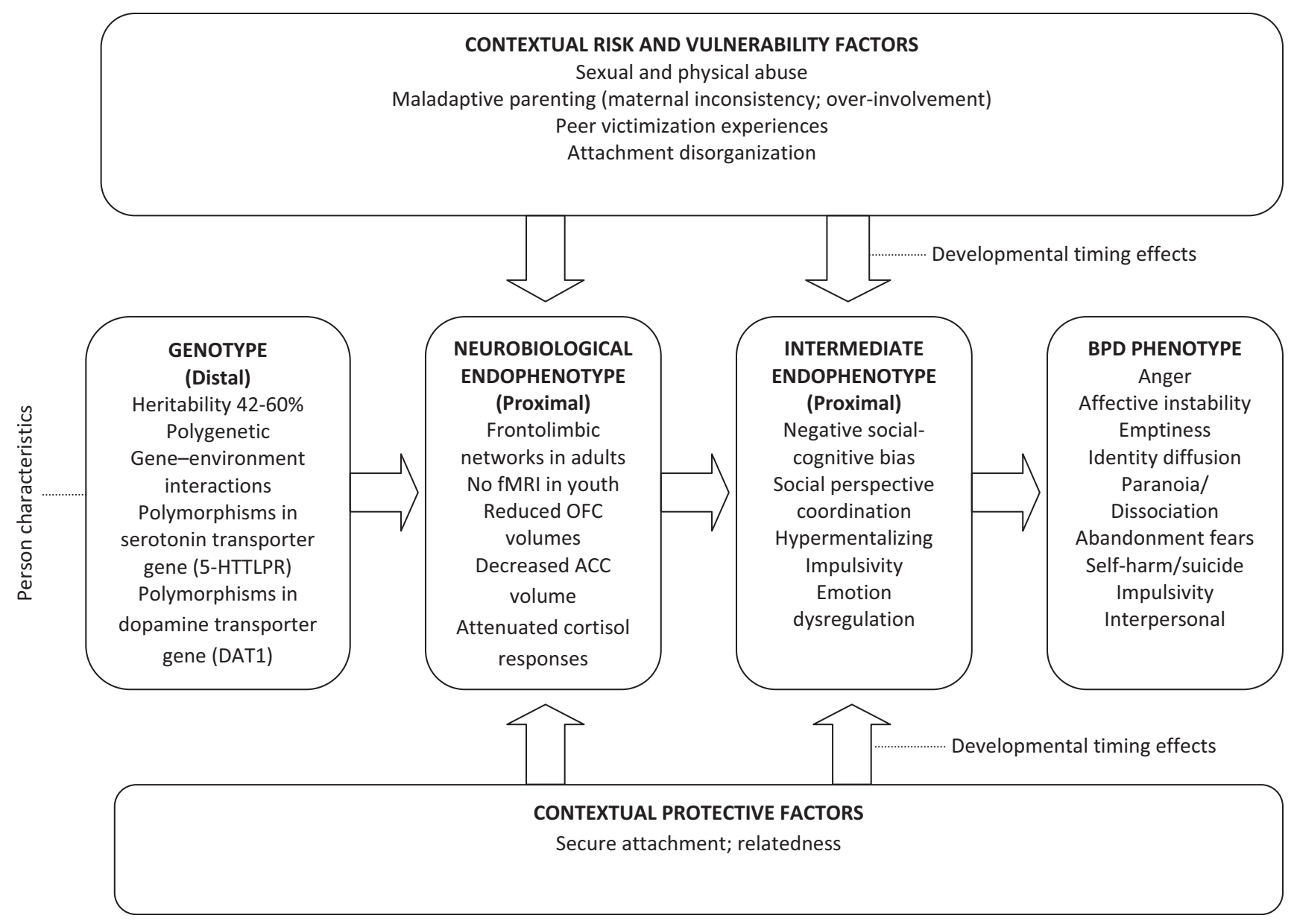

Figure 1 Etiological factors in the development of adolescent BPD 
continuity, where coherence is evident at the level of the behavioral phenotype; Caspi \& Bern, 1990). Consistent with the notion of heterotypic continuity, Stepp, Burke, Hipwell, and Loeber (2012) have described an externalizing pathway to the development of BPD, suggesting that the underlying BPD symptomatology may express itself early on in externalizing behavior, although features of internalizing disorder are also present. At some point in development, the interaction between BPD and externalizing pathology diminishes to make way for a stronger association with internalizing pathology, as evidenced in adult studies (Eaton et al., 2011; James \& Taylor, 2008). Thus, underlying processes of affective dysregulation, impulsivity, and interpersonal problems (including problems in mentalizing) that drive BPD in adolescents will express themselves in behaviors that mimic externalizing problems (outbursts, moodiness, self-harm, substance use, stormy relationships), but as the adolescent matures, these behavioral expressions will attenuate to more closely resemble internalizing distress (anxious-misery) in adulthood, while still retaining externalizing features. We emphasize here again that it is in the confluence of internalizing and externalizing spectra of psychopathology that BPD may be located.

Summary. The literature to date suggests that $1 \%$ $5 \%$ of adolescents meet criteria for BPD, and the average severity of BPD is greater in adolescents than in adults. The rank order stability (i.e. the change in an individual's personality trait relative to other individuals) of BPD symptoms in adolescence is moderate. BPD diagnosis is predictive of future impairment such as traditional Axis I diagnoses, yet BPD symptoms themselves are likely to improve with age. From a developmental psychopathology perspective, the evidence is consistent with the assumption of a range of bidirectional aggravating interactive processes, whereby BPD symptoms increase and are increased by poor life adaptation at least in terms of social relationships, which in turn can generate, and be further worsened by, internalizing and externalizing disorders. To put it quite broadly, the profile of problems characteristic of BPD is likely to generate a negative, bidirectional interaction between the person and his/her social environment where the supportive, resilienceenhancing properties of the social environment are negated, leaving the individual exceptionally vulnerable to both social and biological risk. Thus, clinicians have to balance a delicate tension in assessing patients: on one hand, avoiding labeling acute and potentially transient behaviors as a pervasive personality impairment when these are context-specific and developmentally appropriate; and on the other hand, making sure they identify when the same behavior may be part of a more stable shift in personality functioning. Guidance is provided in this regard in the section on Assessment.

\section{Etiology}

Borderline personality disorder is a complex disorder and it is no surprise that it is associated with a complex etiology. Guided by developmental psychopathology, we have summarized etiological factors in the development of adolescent BPD in Figure 1; many of these factors were evident in the case vignette. Clearly, while myriad risk factors have been identified for BPD, few contextual protective factors have been identified.

Genetic factors. Borderline personality disorder has been shown to be moderately heritable in adults, although specific genes are yet to be identified (Chanen \& Kaess, 2012). Heritability rates of $0.42-$ 0.69 (Distel et al., 2008; Kendler, Myers, \& Reichborn-Kjennerud, 2011; Torgersen et al., 2000) have been demonstrated. In adolescents, Belsky et al. (2012) examined borderline-related features in 1,116 pairs of twins aged 12 and showed that traits were both heritable and associated with harsh parental treatment. Using data on over 1,000 adolescent female twins taking part in the Minnesota Twin Family Study (MTFS), an ongoing population-based, longitudinal study of twins and their families, Bornovalova et al. (2009) found that borderline traits were moderately heritable from age 14 to 24 , with a trend for increased heritability between ages 14 and 18. Importantly, this study also showed that both stability and change of BPD traits were influenced profoundly by genetic factors, and modestly, but increasingly, by nonshared environmental factors; this underscores the etiological significance of young people progressively selecting their own environment, as well as providing support for a diathesisstress approach to BPD, which we will discuss below.

Beyond heritability, only one study has examined genetic polymorphisms associated with adolescent BPD. Hankin et al. (2011) demonstrated in a first study $(N=242)$ and an independent replication sample $(N=144)$ of youth (ages 9-15 years) that carriers of the short allele of the serotonin transporter promoter gene (5-HTTLPR) exhibited the highest levels of BPD traits. Potential candidate genes that have been implicated for adult BPD that may be examined in future adolescent studies include the gene coding for tryptophan hydroxylase (TPH) (Zaboli et al., 2006), which is implicated in impulsive aggression and suicidal behavior, and 5HT2a (Ni et al., 2006), 5HT2c (Ni, Chan, Chan, McMain, \& Kennedy, 2009), and monoamine oxidase (Ni et al., 2007), all of which suggest a serotonergic abnormality (Goodman, Perez-Rodriguez, \& Siever, 2014). 
Neuropeptides. Oxytocin is an important regulator of social cognition and mentalizing, and may be a key modulator of the aberrant attachment and affiliative systems characteristic of BPD (Stanley \& Siever, 2010). While no studies have been conducted in adolescents, early studies in adult BPD (Bartz et al., 2011; Simeon et al., 2011) suggest that oxytocin merits further investigation for its potential treatment implications.

Hypothalamic-pituitary-adrenal axis. In adults with BPD, there is evidence of suppressed or delayed cortisol responses after psychosocial stress (Carrasco et al., 2007; Walter et al., 2008). Evidence of hypothalamic-pituitary-adrenal (HPA) axis abnormalities has also been found in adolescents with BPD. For instance, hyporesponsiveness of cortisol secretion to acute stress was demonstrated by Kaess et al. (2012), and Garner et al. (2007) demonstrated that BPD patients who were exposed to childhood trauma tended to have smaller pituitaries $(-18 \%$ volume) than those with no history of childhood trauma. Consistent with these findings, Jovev et al. (2008) demonstrated that the lifetime number of parasuicidal behaviors was a significant predictor of pituitary volume in first-presentation adolescents with BPD; this suggests that parasuicidal behavior in individuals with BPD might be associated with greater activation of the HPA axis. While these studies are too few to draw firm conclusions, they suggest, consistent with clinical consensus on BPD, that hypersecretion of cortisol may be associated with maladaptive stress responses in the development of the disorder, especially in the presence of a trauma history.

Atypical anterior cingulate cortex (ACC) and ACC/ orbitofrontal cortex coupling. At least 10 neuroimaging (all structural) studies have been conducted in adolescent BPD (for a review, see Goodman et al., 2014). Similar to findings in adults, structural imaging research in adolescents with BPD has demonstrated volume reduction in the frontolimbic network, including the orbitofrontal cortex (Brunner et al., 2010; Chanen, Velakoulis, et al., 2008), and the ACC (Goodman et al., 2011; Whittle et al., 2009). In addition, alterations have been identified in whitematter pathways involved in emotion regulation and emotion recognition (Maier-Hein et al., 2014). While adult studies have demonstrated alterations in amygdala and hippocampus volume (Goodman et al., 2014), adolescent studies have not replicated these findings. Nonreplication of findings was likely due to differences in study methodology, most notably the heterogeneity of samples in terms of pathology (although we acknowledge that nonreplication of findings may reflect true differences). Findings in both adult and adolescent samples are further complicated by the co-occurrence of BPD with trauma-related diagnoses, with patterns of findings apparently varying according to the presence or absence of trauma (Bruehl et al., 2013). Ultimately, we hope that cognitive-neuroscientific findings will clarify the issue of heterogeneity of this diagnosis, which clearly evolves through a number of pathogenic pathways (so-called equifinality).

Social factors in BPD. Social and cultural factors appear to play a significant role in BPD symptomatology. The prevalence of BPD varies considerably across countries and is likely to be affected by secular trends (Fonagy \& Luyten, in press). Low socioeconomic status appears to be an independent risk factor for adolescent BPD (Cohen et al., 2008), although the extent to which this may be mediated by parenting variables is unclear. Both maladaptive transactional parent-child interactions (see Macfie \& Strimpfel, 2014 for a review) and other early childhood adversity have been associated with BPD (see Zanarini \& Wedig, 2014 for a review). While adverse childhood experiences are clearly associated with adolescent BPD, sexual abuse is a weak predictor (Kaess, Parzer, et al., 2013) despite compelling clinical accounts to the contrary. Although the association of adversity and psychopathology is not unique to BPD (so-called multifinality), an increase in trauma across childhood, as well as immediately prior to puberty, appears to specifically characterize BPD (Pietrek, Elbert, Weierstall, Muller, \& Rockstroh, 2013). It has been argued that the interpersonal hypersensitivity characteristic of BPD (Gunderson \& Lyons-Ruth, 2008) may be a consequence of maltreated children adapting to adversity by becoming more sensitive or reactive to threats, to preserve security within their home environment (Davies, Winter, \& Cicchetti, 2006); this heightened vigilance could generate a lack of genuine trust in all kinds of interpersonal communication, leaving them in a state of relative epistemic hypervigilance (Fonagy \& Luyten, in press). This example also illustrates that specific personality disturbances should not be seen as limitations of capacity or deficits, but rather as a way favored by natural selection for development to optimize the child's adaptation to his/her social context, despite the challenges posed by the social context. We have previously suggested that there is likely to be a considerable cost to children contemplating the mental state of adults who hold malevolent and hostile intentions toward them; in such circumstances it may be preferable to forgo reflective considerations, particularly regarding the cognitions of others (Fonagy, Moran, \& Target, 1993). This speculation is consistent with an evolutionary developmental view that suggests that we have to study the likely impact for survival and the costs and benefits (to children) of developing particular mental capacities in particular social contexts (Belsky, 2012; Ellis et al., 2012). Here, we want to emphasize the idea of a 'common final pathway': all these types of adversity seem to cause impairments 
in trust that may bring benefit to the child under some social conditions.

While the historical focus on the family in general and parenting in particular in the etiology of BPD is understandable given the historical intellectual domination of psychoanalysis and social learning theory, the powerful role of social influences, particularly peer groups, is now being acknowledged. Many authorities noted a change in nature of adolescence in the late 20th century (Coleman \& Hendry, 1999) as activity of young people with their family halved between 1986 and 2000 while activity with peers increased (Escofet, 2012). Accordingly, there is an emerging literature suggesting that BPD in adolescents may be associated with bullying, peer rejection (Wolke, Schreier, Zanarini, \& Winsper, 2012), and teen dating violence (Reuter, Sharp, Temple, \& Babcock, 2015). Being bullied exacerbates exposure to adverse family environments (Lereya et al., 2013). In all, the transaction between youth and their environment, whereby they both shape and are shaped by social contexts, in turn being influenced by and influencing the way they experience the social environment and creating and responding to the reactions they evoke, renders the understanding of youth personality psychopathology more complex than most (Shiner \& Caspi, 2012).

Diathesis-stress approaches. Most etiological theories for the development of BPD favor a diathesisstress approach. A prominent etiological model of BPD was originally put forward by Linehan (1993) and more recently expanded by Crowell, Beauchaine, and Linehan (2009). In this model, a complex, heterotypic trajectory from childhood vulnerability to adult BPD begins with heritable trait vulnerabilities in the form of emotional sensitivity and reactivity in the original model (Linehan, 1993), or trait impulsivity in the extended model (Crowell et al., 2009). These trait vulnerabilities result in the acquisition of poor emotion regulation skills primarily through aberrant socialization mechanisms in the family context (i.e. an invalidating family environment), ultimately culminating in the complex disorder of BPD. The focus on trait impulsivity as the key underlying pathogenic process in BPD is also reflected in Paris's (2005) diathesis-stress model of BPD.

From a more psychodynamic perspective, the attachment and mentalization-based theory of BPD (Fonagy \& Luyten, 2009; Fonagy, Target, \& Gergely, 2000) posits that failures of seeing actions in terms of underpinning mental states, or misinterpretations of these, may account for core features of BPD. Importantly, and as captured in the case vignette discussed earlier, Fonagy and colleagues have argued that as the child's attachment relationships have an important role to play in the acquisition of social-cognitive capacities, disruptions of early attachment experiences can derail social-cognitive development, thereby leading to BPD (Sharp \&
Fonagy, 2008). The emergent mentalizing capacity is therefore the result of both genetic factors (inherited theory of mind capacity and sensitive temperament) and environmental factors (adverse family or other environment). Recently, Sharp (2014a) extended this theory by suggesting that mentalizing dysfunction in BPD is present not in the form of failure or suppression, but in the form of excess mentalizing (hypermentalizing). Consistent with the assumption of disturbed social understanding of people's intentions is the striking evidence for difficulties in differentiating and integrating the perspective of the self with the perspectives of others, regardless of context or emotional load (Jennings, Hulbert, Jackson, \& Chanen, 2012), and social information processing anomalies attributed to problems of mentalizing (Hessels, van den Hanenberg, de Castro, \& van Aken, 2014).

The notion of a constitutional diathesis in the form of relational reactivity that interacts with the environment is also evident in Gunderson and LyonsRuth's (2008) gene-environment developmental model. Specifically, hypersensitivity to interpersonal stressors contributes to the development of a disorganized-ambivalent form of attachment, leading to an escalation of problematic transactions between primary caregiver and child and, ultimately, to BPD. As espoused in another diathesis-stress approach to BPD (Zanarini \& Frankenburg, 2007), the caregiving environment is not necessarily in and of itself abnormal or traumatic, but, in interaction with a vulnerable or hyperbolic temperament, may put an individual at risk for developing BPD.

The empirical evidence in support of the above diathesis-stress theories is strong, and we refer readers to recent review articles that summarize empirical support for Linehan's biosocial and Paris's impulsivity-oriented theories (Crowell, Kaufman, \& Beauchaine, 2014; Matusiewicz, Weaverling, \& Lejuez, 2014; Selby, Kranzler, \& Panza, 2014), Fonagy's mentalization-based theory (Fonagy \& Luyten, 2009, in press; Sharp, 2014a), and Gunderson and Lyons-Ruth's gene-environment developmental theory (Lyons-Ruth, 2008). While differences between these theories exist in their specific constructs and processes, they all converge to suggest, consistent with a developmental psychopathology framework, that genetic vulnerabilities interact with complex and dynamic transactional processes between caregiver and child over time, rendering certain individuals more likely to develop features of and/or full-blown BPD in adolescence. Increased demand on capacities for attachment may overwhelm some youths as they negotiate new intimate relationships. The peaking of BPD symptoms in adolescence and young adulthood is thus attributable to factors beyond parental influence.

More studies of gene/biology-environment interactions are now needed. A good example of such a study is that of Distel et al. (2011), which aimed to 
examine whether exposure to life events moderated the genetic architecture of BPD features. Evidence for both gene-environment interaction and correlation was found. Additive genetic influences on BPD features interacted with a history of exposure to sexual assault, with genetic variance being lower in exposed individuals. In individuals who had experienced a divorce/break-up, violent assault, sexual assault, or job loss, environmental variance for BPD features was higher, leading to a lower heritability of $\mathrm{BPD}$ features in exposed individuals.

Summary. Evidence to date supports a view that constitutional factors (e.g. anxious or aggressive temperament) and environmental factors (e.g. risk, trauma, parenting, and the wider social environment of the young person) both have a role in the etiology of BPD. However, they may be most powerful in combination because they exert influence on each other. Genes mark a vulnerability, and adversity in the social environment undoubtedly triggers further genetic propensities. One facet of constitutional disadvantage is likely to be greater sensitivity to negative environmental perturbations (Belsky, 2012). Emotional dysregulation may be an indication of this potential constitutional vulnerability. Negative social experiences readily overwhelm these individuals' capacity to assimilate and accommodate to the environment. The same genetic vulnerability is also likely to increase the potential of an individual to benefit from positive experiences under normal circumstances. Beyond a certain point, individuals who are sensitive to their social environment are likely to take an adaptive position of self-protection, whereby they disengage their capacity to attend to and respond appropriately to social cues. They cease to learn from experience in the sense of being able to change (update) their mental representations and coping strategies in response to experience. This position, which we have termed elsewhere epistemic hypervigilance (Fonagy \& Luyten, in press), leaves the individual impervious to positive events that would normally strengthen a person and make for greater resilience. Interpersonal hypersensitivity and hypermentalizing may be seen as compensatory strategies or direct consequences of this adaptation, attempting to create distance between the self and social experience. We also assume that opposite processes (secure attachment, optimal mentalizing, and epistemic trust) would protect an individual from developing BPD.

\section{Assessment for early identification, prevention, and treatment}

Assessment of BPD may take place either in the context of early identification and prevention, or in the context of treatment. Early identification assessment must be considered in the context of prevention science (Mrazek \& Haggerty, 1994). Gordon's (1983) framework is the gold standard in this regard. In this framework, distinctions are drawn between universal preventive measures, which are considered desirable for everybody in an eligible population (e.g. an adequate diet, the use of seatbelts in vehicles, etc.). Selective preventive measures are desirable only for a subgroup of the population whose risk of becoming ill is above average, for instance, the biological offspring of parents with a given disease. Finally, indicated preventive measures, often referred to by clinicians as early intervention (Mrazek \& Haggerty, 1994), apply to those who, on examination, show subthreshold signs and symptoms of a disorder, but do not yet meet the definition of a 'case', thereby identifying them as being at high risk for the future development of the illness (Chanen \& McCutcheon, 2013). The goal of screening programs for early signs and symptoms of a disease therefore falls into the category of indicated preventive measures.

Universal and selective prevention. Currently, there are no known universal preventive measures for $\mathrm{BPD}$, and the evidence for selective preventive measures is questionable. This is not to say that there is a lack of research focusing on identifying the risk factors associated with BPD. What is lacking, however, is specificity of risk factors related to BPD compared to other psychopathology. Therefore, the selective preventive measures that we discuss below are tentative and in need of further research. At best, they are currently suited for consideration by clinicians as a justification for further clinician follow-up rather than a justification for selective or indicated prevention. An obvious candidate risk factor that deserves future research in this regard is status as biological offspring of mothers with BPD (Macfie \& Swan, 2009; Sharp \& Romero, 2007; Weiss et al., 1996). Given moderate rates of heritability, and the known challenges for mothers with BPD in parenting their children, risk may be elevated for this group. Other risk factors as proposed in the etiological models discussed above (see Figure 1) and prospective studies (as summarized in Table 1) include core diagnostic features (in particular identity disturbance, inappropriate anger, chronic feelings of emptiness, self-harm), childhood disorders (in particular attention-deficit/hyperactivity disorder; see Stepp, Whalen, \& Pedersen, 2014 for a review), and problem behavior (controlling and coercive behaviors toward attachment figures, poorly identified sense of self, hostile and distrustful view of the world, relational aggression, outbursts of anger, affective instability). In addition, preliminary research suggests that there may be potential in evaluating personality traits in children that may be characteristic of BPD in later life. Recent work from De Clercq, van Leeuwen, van den Noortgate, de Bolle, and de Fruyt (2009) and De Clercq, Decuyper, and De Caluwé (2014) has suggested that high levels of the following early maladaptive personality traits may be indicative of later BPD in adolescents: hyper-expressive traits, impulsivity, 
irritable-aggressive traits, risk behavior, affective lability, ineffective stress coping, anxious traits, lack of self-confidence, insecure attachment, depressive traits, and paranoid traits. This approach is supported by cross-sectional (Gratz et al., 2009; Kaess, von Ceumern-Lindenstjerna, et al., 2013) and prospective (Crawford, Cohen, Chen, Anglin, \& Ehrensaft, 2009; Crowell et al., 2009) studies. Finally, a risk profile that may hold promise for selective preventive efforts pending further research is evidence for BPD as a disorder of confluence between internalizing and externalizing symptoms (Eaton et al., 2011; James \& Taylor, 2008; Sharp, 2014b), as discussed earlier. Children often present with predominantly externalizing or internalizing profiles. If both are equally endorsed, especially in the context of other known correlates of BPD, further assessment for BPD may be indicated.

Indicated prevention. Currently, the evidence in support of indicated prevention is stronger than that for universal and selective prevention. In this regard, we discuss recent advances in research for the assessment of borderline symptoms in adolescents. These tools may be used to identify adolescents meeting full criteria for BPD (for the purposes of treatment) or subthreshold BPD (for the purposes of indicated prevention or early identification). Specifically, Chanen, McCutcheon, and Kerr (2014) propose the presence of three borderline criteria as justification for inclusion in indicated preventive programs.

Assessment should begin with competent clinical evaluation utilizing standard psychiatric nomenclature (i.e. DSM-5 Section II). Clinical assessment should also be guided by what is known about the etiology of BPD (see Figure 1 and Table 1). In addition to more conventional clinical assessment based on Section II of DSM-5, clinicians may also begin to rely on the new DSM-5 Section III classification system, which takes a dimensional trait-based approach in clinical assessment. This approach would require clinicians to assign a score on several dimensions of personality functioning instead of deciding whether a patient is above or below the clinical threshold for a particular disorder. Given that a systematic and standardized system for clinician interview-based ratings of dimensional trait attributes based on DSM-5 is still to be developed, clinicians may rely on self-report measures of PD pathology to determine a patient's location on a trait continuum. However, consistent with a developmental psychopathology model of psychiatric disorder, we do not believe PD can be altogether reduced to self-identified traits alone, because self-identified trait attributes constitute only one level of personality functioning (i.e. the self-reported trait level) and may disregard other levels of functioning that are more impenetrable to subjective assessment. Thus, self-identified trait attributes cannot account for the dynamic processes that give rise to the discrepancies between self-identified traits and behavioral manifestations typically characteristic of PDs (Luyten \& Blatt, 2011). In all, in order for categorical and dimensional approaches to be effectively integrated, multiple method assessment will become standard practice in $\mathrm{PD}$ diagnostic procedures.

Accordingly, clinical assessment may be complemented with assessment tools developed specifically to assess adolescent BPD. Although assessment tools were formerly unavailable, the past decade has seen a significant increase in psychometric studies validating assessment tools for DSM-5 Section II BPD in children and adolescents (Table 2). While more research is needed to determine the longterm predictive power of these measures, these studies provide guidance for the use of measures in clinical settings.

The Child Interview for DSM-IV Borderline Personality Disorder (CI-BPD; Zanarini, 2003) is an interview-based measure administered by a trained interviewer. It has nine stem questions rated on a three-point scale and takes 30-45 min to complete. The Shedler-Westen Assessment Procedure for Adolescents, Version II (SWAP-II-A; Westen, Dutra, \& Shedler, 2005) is used by clinically experienced observers in the context of either a thorough examination of a patient using a systematic clinical research interview, or in a professional assessment or ongoing therapeutic engagement. The clinician sorts (rank orders) 200 personality statements into eight categories based on their applicability to the patient, thereby deriving a diagnosis of BPD. The Personality Assessment Inventory Borderline subscale (PAI-BOR; Morey, 2007) is a 20-item subscale from a 264-item self-report questionnaire that requires adolescents to rate their behavior, thoughts, and feelings on a four-point Likert scale. The Borderline Personality Disorder Features Scale for Children (BPFSC; Crick, Murray-Close, \& Woods, 2005) was adapted from the PAI-BOR to be more developmentally sensitive for younger children. It is a 24-item self-report measure for children aged 9 and older, rated on a five-point Likert scale. A parent version (BPFSC-P; Sharp, Mosko, Chang, \& Ha, 2011) as well as an 11-item version for resourceconstrained settings (BPFSC-11; Sharp, Steinberg, Temple, \& Newlin, 2014) were developed. The McLean Screening Instrument for BPD (MSI-BPD; Zanarini et al., 2003) is a 10-item self-report yes/ no measure that provides a brief screening assessment of the number of BPD criteria met. Finally, the Borderline Personality Questionnaire (BPQ; Poreh et al., 2006) is an 80-item self-report measure with true/false response options. Please refer to Table 2 for psychometric properties of these measures.

In addition to the above DSM-based measures, several trait measures that may be useful for DSM-5 Section III assessment have been developed and used in adolescents. These may also be considered in the assessment of BPD in adolescents. The Minnesota 
Table 2 Psychometric studies of assessment tools for DSM-based adolescent BPD

\begin{tabular}{|c|c|c|c|c|}
\hline Measure & $\begin{array}{l}\text { Internal } \\
\text { consistency }\end{array}$ & $\begin{array}{l}\text { Interrater } \\
\text { reliability }\end{array}$ & Factor structure & External validity \\
\hline \multicolumn{5}{|l|}{ CI-BPD } \\
\hline Zanarini (2003) & 0.81 & $0.65-0.93$ & Not reported & \\
\hline Sharp et al. (2012) & 0.80 & 0.89 & Unidimensional & $\begin{array}{l}\text { Associates with PAI-BOR, clinician diagnosis, } \\
\text { BPFS-C, BPFS-P, internalizing and } \\
\text { externalizing problems } \kappa=0.34 \text { with } \\
\text { clinician diagnosis }\end{array}$ \\
\hline Michonski et al. (2013a) & 0.78 & $\begin{array}{l}\text { Not } \\
\text { reported }\end{array}$ & Unidimensional & $\mathrm{N} / \mathrm{A}$ \\
\hline \multicolumn{5}{|l|}{ SWAP-A-II } \\
\hline Westen et al. (2005) & Not reported & 0.60 & Not reported & $r=.68$ with DSM-5 symptom count $\mathrm{AUC}=0.84$ \\
\hline \multicolumn{5}{|l|}{ PAI-BOR } \\
\hline Morey (2007) & $0.85-0.87$ & $\mathrm{~N} / \mathrm{A}$ & Four-factor & $\begin{array}{l}\text { Associated with range of other BPD relevant } \\
\text { pathology }\end{array}$ \\
\hline Chang, Sharp, and Ha (2011) & 0.88 & $\mathrm{~N} / \mathrm{A}$ & Not reported & $\begin{array}{l}\text { Sensitivity } 0.85 \\
\text { Specificity } 0.84\end{array}$ \\
\hline \multicolumn{5}{|l|}{ BPFSC-P } \\
\hline Sharp et al. (2011) & 0.90 & $\mathrm{~N} / \mathrm{A}$ & Not reported & $\begin{array}{l}\text { Correlates with BPFS-C, internalizing and } \\
\text { externalizing problems }\end{array}$ \\
\hline \multicolumn{5}{|l|}{ BPFSC-11 } \\
\hline Sharp et al. (2014) & 0.85 & $\mathrm{~N} / \mathrm{A}$ & Unidimensional & $\begin{array}{l}\text { Sensitivity } 0.740 \\
\text { Specificity } 0.714\end{array}$ \\
\hline \multicolumn{5}{|l|}{ MSI-BPD } \\
\hline Chanen, Jovev, et al. (2008) & 0.78 & $\mathrm{~N} / \mathrm{A}$ & Not reported & $\begin{array}{l}\text { Sensitivity } 0.68 \\
\text { Specificity } 0.75 \\
\kappa=0.35 \text { with SCID-II } \\
\text { NPV }=0.89\end{array}$ \\
\hline \multicolumn{5}{|l|}{$\mathrm{BPQ}$} \\
\hline Chanen, Jovev, et al. (2008) & 0.92 & $\mathrm{~N} / \mathrm{A}$ & Not reported & $\begin{array}{l}\text { Sensitivity } 0.68 \\
\text { Specificity } 0.90 \\
\kappa=0.57 \text { with SCID-II } \\
\text { NPV }=0.91\end{array}$ \\
\hline
\end{tabular}

Note. N/A, Not available; NPV, Negative Predictive Value (the probability that a person does not have a disease).

Multiphasic Personality Inventory-Adolescent version (MMPI-A; Butcher et al., 1992) is a 478-item true/ false self-report inventory designed to assess the social, emotional, and behavioral functioning of adolescents between the ages of 14 and 18 , and has been examined in one study of adolescent BPD (Archer, Ball, \& Hunter, 1985). The Dimensional Personality Symptom Item Pool (DIPSI; De Clercq, De Fruyt, Van Leeuwen, \& Mervielde, 2006) comprises 172 items that are structured into 27 maladaptive personality facets, hierarchically organized in four broad personality dimensions (Disagreeableness, Emotional Instability, Introversion, and Compulsivity). Finally, an adolescent version of the Personality Inventory for DSM-5 (PID-5; Krueger, Derringer, Markon, Watson, $\&$ Skodol, 2012) has recently been validated for use in adolescents (De Clercq, De Fruyt, et al., 2014; De Clercq, Decuyper, et al., 2014). The PID-5 includes 220 items to be rated on a four-point Likert scale, structured into 25 empirically derived lower level trait pathology facets that assess the traits for DSM-5 Section III.
Summary. Despite several valid and reliable diagnostic tools for evaluating adolescent BPD, the field still lacks an evidence-based approach to deciding which assessment to use in which setting and the sequence of assessments needed for optimal precision in the diagnostic process. In the meantime, practitioners will first and foremost rely on competent clinical evaluation utilizing standard psychiatric nomenclature (i.e. DSM-5 Section II) and may complement clinical assessment with the screening measures such as the BPFSC, BPFSC11 , MSI-BPD, or the PAI-BOR, followed by more indepth assessments such as the CI-BPD and the SWAP-A.

\section{Intervention}

Given the reluctance to diagnose BPD in adolescence, as discussed earlier, it is not surprising that BPD in adolescents is not regularly assessed for or treated in clinical settings in most countries. Here, we argue not only for the integration of evidence-based treatment 


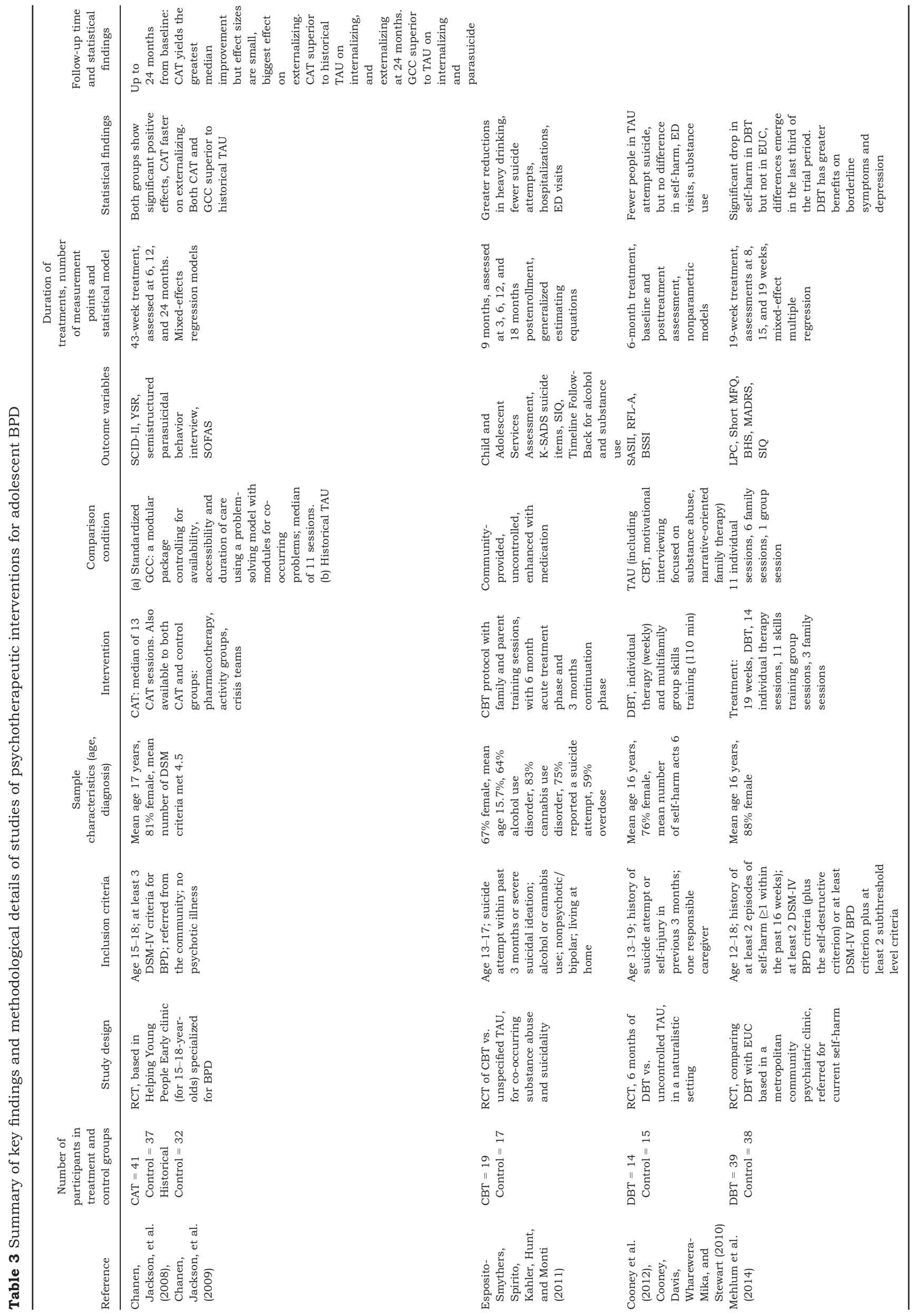




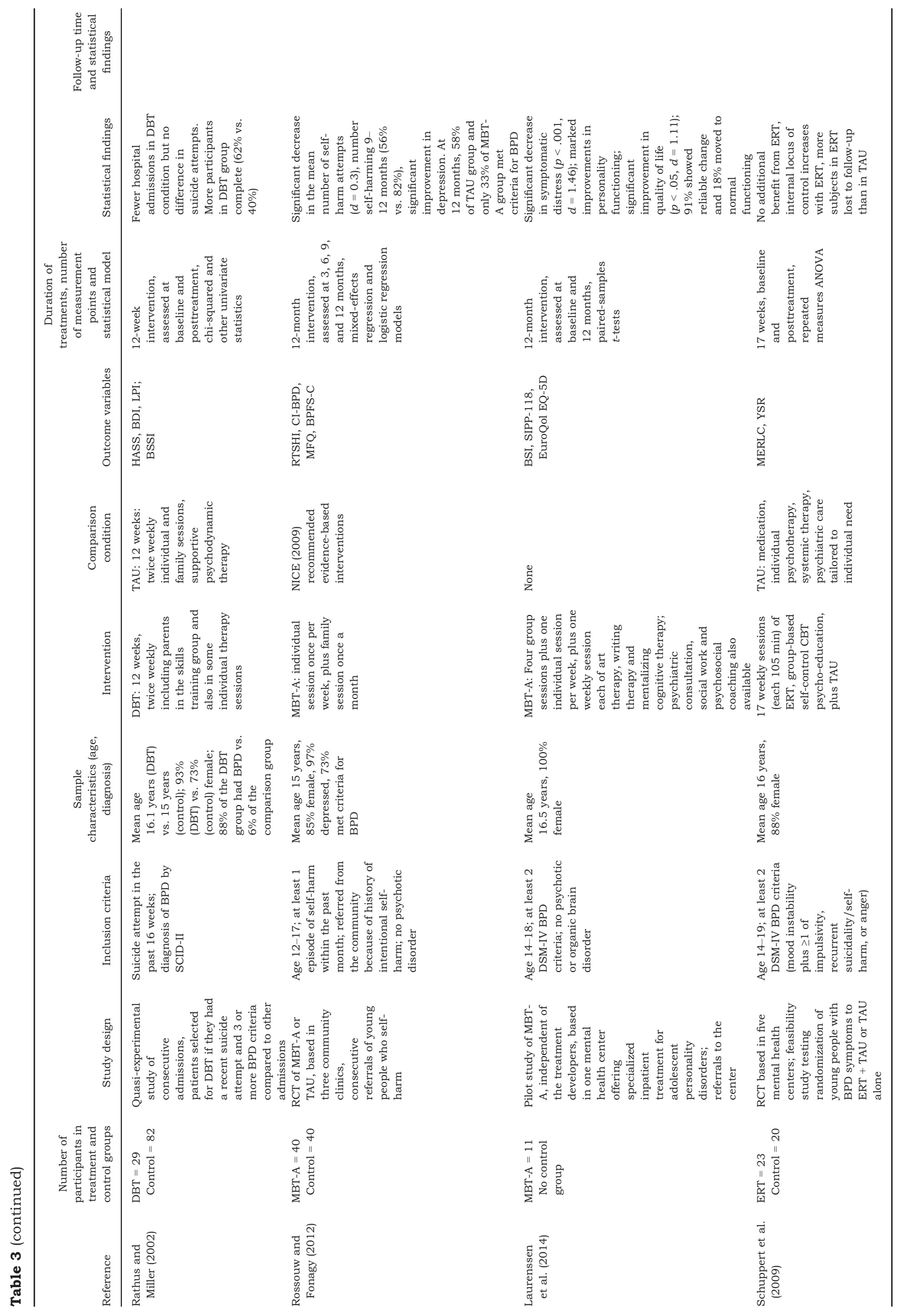



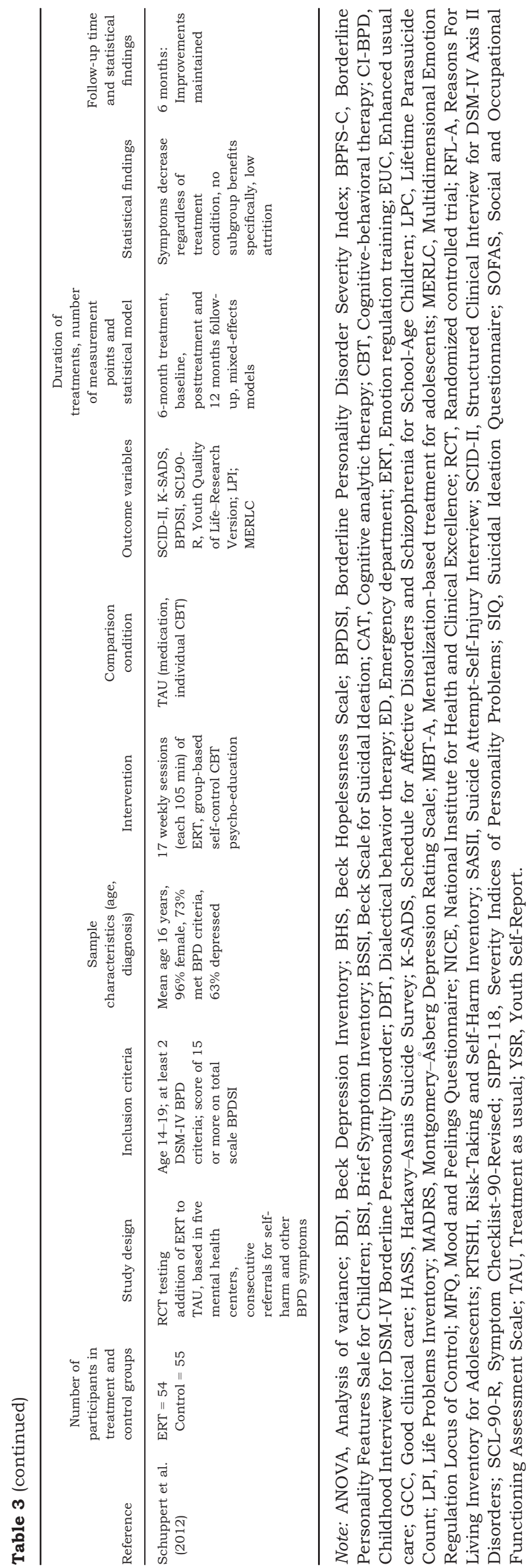

into standard clinical practice for adolescents but also for the development of early intervention strategies. We also emphasize that the tradition of individual psychotherapy for BPD may be expanded to include service delivery models of high-quality care that may be as effective as 'branded' psychotherapies (Bateman \& Fonagy, 2009; Chanen et al., 2014), particularly for individuals without additional diagnoses of co-occurring PDs (Bateman \& Fonagy, 2013). Table 3 summarizes key findings and methodological details of intervention studies.

Early intervention. The notion of early intervention for adolescent BPD has been promoted by Chanen $\&$ McCutcheon (2013) for over 15 years. They suggest that neither stand-alone, universal, nor selective prevention of BPD is currently practical, and argue for indicated prevention (targeting adolescents with early features of BPD). Their program, Helping Young People Early (HYPE), is a comprehensive and integrated indicated prevention and early intervention program for youth (15-25 years of age); it includes adolescents who meet two or more BPD criteria, plus a childhood risk factor. More recently, inclusion criteria for HYPE have been specified as meeting three BPD criteria with no risk factors (Chanen et al., 2014). HYPE includes both a service model and individual therapy, and incorporates the principles of cognitive analytic therapy (CAT) into both components.

A further early intervention program for BPD is the Dutch Emotion Regulation Training (ERT) treatment program (Schuppert et al., 2009). ERT is an adaptation of Systems Training for Emotional Predictability and Problem Solving (STEPPS; Blum et al., 2008), a 20-week manual-based group treatment program for outpatients with BPD that combines cognitivebehavioral elements and skills training with a systems component. Both HYPE and ERT provide support for the potential of early intervention for BPD.

Evidence-based intervention programs. Cognitive analytic therapy (CAT; Ryle \& Kerr, 2002) was the first individual therapy to be tested in a randomized controlled trial (RCT) for adolescent BPD and was evaluated in the context of the HYPE program (Chanen \& McCutcheon, 2013; Chanen, Jackson, et al., 2009; Chanen, McCutcheon, et al., 2009). CAT is time-limited and transdiagnostic, and integrates elements of psychoanalytic object relations theory and cognitive psychology. Compared to treatment as usual, CAT has demonstrated effectiveness and more rapid recovery, although differences were not as marked at 2-year follow-up (Chanen, Jackson, et al., 2009). The CAT model is currently being disseminated in Europe.

Mentalization-based treatment (MBT; Bateman \& Fonagy, 2009) shares many common features with CAT (Bateman, Ryle, Fonagy, \& Kerr, 2007), and has been adapted for use in adolescents. This therapy assumes that the development of BPD in adolescence 
and its treatment is grounded in a phase-specific compromise in the capacity to mentalize that occurs during adolescence (Fonagy et al., 2014). MBT for adolescents (MBT-A), which incorporates monthly sessions of $M B T$ for families (MBT-F), has been shown to be effective in an RCT in a sample of self-harming adolescents (most of whom met criteria for BPD; Rossouw \& Fonagy, 2012). MBT-A was more effective than treatment as usual in reducing self-harm and depression. This superiority was explained by improved mentalizing and reduced attachment avoidance, and reflected improvement in emergent BPD symptoms and traits.

Dialectical behavior therapy (DBT; Linehan, 1993) has been adapted for use in adolescents. DBT synthesizes a change orientation from behavior therapy with an acceptance orientation from Zen philosophy specifically to target the emotional dysregulation, distress tolerance, and interpersonal difficulties in BPD. DBT has been evaluated in adolescents with nonsuicidal self-injury (NSSI) and two BPD criteria in Norway (Mehlum et al., 2012), adolescents with a history of NSSI and suicide attempts in New Zealand (Cooney et al., 2012), and adolescents with bipolar disorder (Goldstein, Axelson, Birmaher, \& Brent, 2007). STEPPS, which has been developed from DBT, has also been evaluated in a small-scale study in the United Kingdom in adolescents with BPD, and has shown strong potential for this population (Harvey, Blum, Black, Burgess, \& Henley-Cragg, 2014).

Finally, transference-focused psychotherapy (TFP; Clarkin et al., 2001) has been adapted for use in adolescents. TFP is based on contemporary psychoanalytic object relations theory as developed by Kernberg. TFP-A is a manualized psychodynamic treatment for borderline adolescents delivered in individual sessions, ideally twice a week but not less often than once a week (Normandin, Ensink, Yeomans, \& Kernberg, 2014). Although commonly used with adolescents with BPD, TFP-A has not yet been evaluated in an RCT.
Summary. Clearly, the climate is favorable for the assessment, diagnosis and treatment of adolescent BPD. On the basis of current evidence, we distil the following common factors of successful interventions for adolescents with BPD: (a) extensive effort to maintain engagement in treatment (validation in conjunction with emphasis on the need to address behaviors that interfere with therapy), (b) a valid (evidencebased) model of pathology that is explained and feels relevant to the patient, (c) an active therapist stancethat is, an explicit intent to validate and demonstrate empathy and generate a strong attachment relationship, (d) the reinforcement of epistemic trust (Sperber et al., 2010) - that is, facilitating a belief in the possibility that something can be learned in therapy, (e) focus on emotion processing and the connection between action and feeling (e.g. suicidal ideation is associated with abandonment feelings), (f) inquiry into patients' mental states (behavioral analysis, clarification, confrontation), (g) a structure that provides increased activity, proactivity, and self-agency (i.e. the therapist avoids the expert stance and rather 'sits side by side' with the adolescent in a partnership), (h) the structure is manualized and adherence to the manual is monitored, (i) both therapist and client must feel a commitment to the approach, and (j) supervision is essential to identify deviation from the manualized structure and provide support for adherence.

\section{Conclusion}

This review provided up-to-date information on the phenomenology, prevalence, associated clinical problems, etiology, and interventions for adolescent BPD. We hope that by doing so we have dispelled some of the entrenched ideas regarding PD in adolescents. It is only through early active assessment and identification of youngsters with these problems that a lifetime of personal suffering and health system burden can be reduced or altogether avoided.

\section{Key points}

\section{Key practitioner message}

- BPD constitutes a valid and reliable diagnosis in adolescence.

- BPD should be included in routine clinical assessment of adolescents and validated measures are available to assist with this.

- Evidence to date supports a diathesis-stress model of BPD, whereby constitutional factors (e.g. anxious or aggressive temperament) and environmental factors (e.g. risk, trauma, parenting, and the wider social environment) interact dynamically over time in the etiology of BPD.

- A variety of evidence-based approaches are now available to treat BPD and related clinical problems in youngsters. 


\section{Areas for future research}

- Future research should focus on establishing an evidence-based sequence of assessments for optimal precision in the diagnostic process relevant to different treatment settings.

- While RCTs have been conducted for adolescent BPD, more research is needed to firmly establish different treatment approaches, with a strong focus on early intervention and prevention.

- Longitudinal community-based studies are necessary to elucidate the complex transactional processes that contribute to the development of BPD and may serve as early risk factors for the disorder.

\section{Acknowledgements}

Work on this review was supported by funding from the McNair Foundation, and the American Psychoanalytic Association awarded to C.S. to support research at the Adolescent Treatment Program of the Menninger Clinic, and funding from the U.K. National Institute of Health Research (Senior Investigator Award NF-SI-051010228) awarded to P. F. The authors have declared that they have no competing or potential conflicts of interest in relation to this review.

\section{Correspondence}

Peter Fonagy, Research Department of Clinical, Educational and Health Psychology, University College London, Gower Street, London WC1E 6BT, UK; Email: p.fonagy@ucl.ac.uk

\section{Note}

1. We have been in favor of this approach for some time (Gunderson \& Elliott, 1985; Higgitt \& Fonagy, 1992) based on epidemiological findings replicated over decades that BPD, more than other PDs, was more likely to be accompanied by co-occurring mental disorders, suggesting that the diagnosis signaled a vulnerability to developing further mental health problems (analogous to a deficiency in some psychological equivalent of the immune system). Only recently has this suggestion found empirical support in the proposal of an overarching common factor indicating the severity of psychopathology and its likely course (Caspi et al., 2013).

\section{References}

Akiskal, H.S., Chen, S.E., Davis, G.C., Puzantian, V.R., Kashgarian, M., \& Bolinger, J.M. (1985). Borderline: An adjective in search of a noun. Journal of Clinical Psychiatry, 46, 41-48.

Allen, J.P., Insabella, G., Porter, M.R., Smith, F.D., Land, D., \& Phillips, N. (2006). A social-interactional model of the development of depressive symptoms in adolescence. Journal of Consulting and Clinical Psychology, 74, 55-65.

American Psychiatric Association (1968). Diagnostic and statistical manual of mental disorders, 2nd edn. Washington, DC: Author.

American Psychiatric Association (2000). Diagnostic and statistical manual of mental disorders (4th, text rev ed). Washington, DC: Author.
American Psychiatric Association (2013). Diagnostic and statistical manual of mental disorders, 5th edn. Washington, DC: Author.

Archer, R.P., Ball, J.D., \& Hunter, J.A. (1985). MMPI characteristics of borderline psychopathology in adolescent inpatients. Journal of Personality Assessment, 49, 47-55.

Arens, E.A., Stopsack, M., Spitzer, C., Appel, K., Dudeck, M., Volzke, H., ... \& Barnow, S. (2013). Borderline personality disorder in four different age groups: A cross-sectional study of community residents in Germany. Journal of Personality Disorders, 27, 196-207.

Bartz, J., Simeon, D., Hamilton, H., Kim, S., Crystal, S., Braun, A., ... \& Hollander, E. (2011). Oxytocin can hinder trust and cooperation in borderline personality disorder. Social Cognitive and Affective Neuroscience, 6, 556-563.

Bateman, A., \& Fonagy, P. (2009). Randomized controlled trial of outpatient mentalization-based treatment versus structured clinical management for borderline personality disorder. American Journal of Psychiatry, 166, 13551364.

Bateman, A., \& Fonagy, P. (2013). Impact of clinical severity on outcomes of mentalisation-based treatment for borderline personality disorder. British Journal of Psychiatry, 203, 221 227.

Bateman, A.W., Ryle, A., Fonagy, P., \& Kerr, I.B. (2007). Psychotherapy for borderline personality disorder: Mentalization based therapy and cognitive analytic therapy compared. International Review of Psychiatry, 19, 51-62.

Becker, D.F., Grilo, C.M., Edell, W.S., \& McGlashan, T.H. (2002). Diagnostic efficiency of borderline personality disorder criteria in hospitalized adolescents: Comparison with hospitalized adults. American Journal of Psychiatry, 159, 2042-2047.

Becker, D.F., McGlashan, T.H., \& Grilo, C.M. (2006). Exploratory factor analysis of borderline personality disorder criteria in hospitalized adolescents. Comprehensive Psychiatry, 47, 99105.

Belsky, J. (2012). The development of human reproductive strategies: Progress and prospects. Current Directions in Psychological Science, 21, 310-316.

Belsky, D.W., Caspi, A., Arseneault, L., Bleidorn, W., Fonagy, P., Goodman, M., ... \& Moffitt, T.E. (2012). Etiological features of borderline personality related characteristics in a birth cohort of 12-year-old children. Development and Psychopathology, 24, 251-265.

Bernstein, D.P., Cohen, P., Velez, C.N., Schwab-Stone, M., Siever, L.J., \& Shinsato, L. (1993). Prevalence and stability of the DSM-III-R personality disorders in a communitybased survey of adolescents. American Journal of Psychiatry, 150, 1237-1243.

Blais, M.A., Hilsenroth, M.J., \& Fowler, J.C. (1999). Diagnostic efficiency and hierarchical functioning of the DSM-IV borderline personality disorder criteria. Journal of Nervous and Mental Disease, 187, 167-173.

Blum, N., St John, D., Pfohl, B., Stuart, S., McCormick, B., Allen, J., .. \& B Black, D.W. (2008). Systems Training for Emotional Predictability and Problem Solving (STEPPS) for 
outpatients with borderline personality disorder: A randomized controlled trial and 1-year follow-up. American Journal of Psychiatry, 165, 468-478.

Bornovalova, M.A., Hicks, B.M., Iacono, W.G., \& McGue, M. (2009). Stability, change, and heritability of borderline personality disorder traits from adolescence to adulthood: A longitudinal twin study. Development and Psychopathology, 21, 1335-1353.

Bradley, R., Zittel Conklin, C., \& Westen, D. (2005). The borderline personality diagnosis in adolescents: Gender differences and subtypes. Journal of Child Psychology and Psychiatry, 46, 1006-1019.

Bruehl, H., Preissler, S., Heuser, I., Heekeren, H.R., Roepke, S., \& Dziobek, I. (2013). Increased prefrontal cortical thickness is associated with enhanced abilities to regulate emotions in PTSD-free women with borderline personality disorder. PLoS One, 8, e65584.

Brunner, R., Henze, R., Parzer, P., Kramer, J., Feigl, N., Lutz, K., ... \& Stieltjes, B. (2010). Reduced prefrontal and orbitofrontal gray matter in female adolescents with borderline personality disorder: Is it disorder specific? NeuroImage, 49, 114-120.

Butcher, J.N., Williams, C.L., Graham, J.R., Archer, R.P., Tellegen, A., Ben-Porath, Y.S., .. \& Kaemmer, B. (1992). Minnesota Multiphasic Personality Inventory-Adolescent (MMPI-A): Manual for administration, scoring, and interpretation. Minneapolis: University of Minnesota Press.

Cailhol, L., Jeannot, M., Rodgers, R., Guelfi, J.D., Perez-Diaz, F., Pham-Scottez, A., ... \& Speranza, M. (2013). Borderline personality disorder and mental healthcare service use among adolescents. Journal of Personality Disorders, 27, 252-259.

Carlson, E.A., Egeland, B., \& Sroufe, L.A. (2009). A prospective investigation of the development of borderline personality symptoms. Development and Psychopathology, 21, 13111334.

Carrasco, J.L., Diaz-Marsa, M., Pastrana, J.I., Molina, R., Brotons, L., Lopez-Ibor, M.I., ... \& Lopez-Ibor, J.J. (2007). Hypothalamic-pituitary-adrenal axis response in borderline personality disorder without post-traumatic features. British Journal of Psychiatry, 190, 357-358.

Caspi, A., \& Bern, D. (1990). Personality continuity and change across the life course. In L.A. Pervin (Ed.), Handbook of personality: Theory and research (pp. 549-575). New York: Guilford Press.

Caspi, A., Houts, R.M., Belsky, D.W., Goldman-Mellor, S.J., Harrington, H., Israel, S., ... \& Moffitt, T.E. (2013). The p factor: One general psychopathology factor in the structure of psychiatric disorders? Clinical Psychological Science, 2, 119137.

Chabrol, H., Chouicha, K., Montovany, A., Callahan, S., Duconge, E., \& Sztulman, H. (2002). Troubles de la personnalite dans un echantillon non clinique d'adolescents [Personality disorders in a nonclinical sample of adolescents]. Encephale-Revue de Psychiatrie Clinique Biologique et Therapeutique, 28, 520-524.

Chanen, A.M., Jackson, H.J., McCutcheon, L.K., Jovev, M., Dudgeon, P., Yuen, H.P., ... \& McGorry, P.D. (2008). Early intervention for adolescents with borderline personality disorder using cognitive analytic therapy: Randomised controlled trial. British Journal of Psychiatry, 193, 477-484.

Chanen, A.M., Jackson, H.J., McCutcheon, L.K., Jovev, M., Dudgeon, P., Yuen, H.P., ... \& McGorry, P.D. (2009). Early intervention for adolescents with borderline personality disorder: Quasi-experimental comparison with treatment as usual. Australian and New Zealand Journal of Psychiatry, 43, 397-408.

Chanen, A.M., Jackson, H.J., McGorry, P.D., Allot, K.A., Clarkson, V., \& Yuen, H.P. (2004). Two-year stability of personality disorder in older adolescent outpatients. Journal of Personality Disorders, 18, 526-541.
Chanen, A.M., Jovev, M., Djaja, D., McDougall, E., Yuen, H.P., Rawlings, D., ... \& Jackson, H.J. (2008). Screening for borderline personality disorder in outpatient youth. Journal of Personality Disorders, 22, 353-364.

Chanen, A.M., Jovev, M., \& Jackson, H.J. (2007). Adaptive functioning and psychiatric symptoms in adolescents with borderline personality disorder. Journal of Clinical Psychiatry, 68, 297-306.

Chanen, A.M., \& Kaess, M. (2012). Developmental pathways to borderline personality disorder. Current Psychiatry Reports, 14, 45-53.

Chanen, A.M., \& McCutcheon, L.K. (2008). Personality disorder in adolescence: The diagnosis that dare not speak its name. Personality and Mental Health, 2, 35-41.

Chanen, A.M., \& McCutcheon, L. (2013). Prevention and early intervention for borderline personality disorder: Current status and recent evidence. British Journal of Psychiatry Supplement, 54, s24-s29.

Chanen, A.M., McCutcheon, L.K., Germano, D., Nistico, H., Jackson, H.J., \& McGorry, P.D. (2009). The HYPE Clinic: An early intervention service for borderline personality disorder. Journal of Psychiatric Practice, 15, 163-172.

Chanen, A.M., McCutcheon, L.K., Jovev, M., Jackson, H.J., \& McGorry, P.D. (2007). Prevention and early intervention for borderline personality disorder. Medical Journal of Australia, 187(7 Suppl), S18-S21.

Chanen, A.M., McCutcheon, L., \& Kerr, I.B. (2014). HYPE: A cognitive analytic therapy-based prevention and early intervention program for borderline personality disorder. In C. Sharp \& J.L. Tackett (Eds.), Handbook of borderline personality disorder in children and adolescents (pp. 261383). New York: Springer.

Chanen, A.M., Velakoulis, D., Carison, K., Gaunson, K., Wood, S.J., Yuen, H.P., ...\& Pantelis, C. (2008). Orbitofrontal, amygdala and hippocampal volumes in teenagers with firstpresentation borderline personality disorder. Psychiatry Research, 163, 116-125.

Chang, B., Sharp, C., \& Ha, C. (2011). The criterion validity of the Borderline Personality Features Scale for Children in an adolescent inpatient setting. Journal of Personality Disorders, 25, 492-503.

Chen, H., Cohen, P., Crawford, T.N., Kasen, S., Guan, B., \& Gorden, K. (2009). Impact of early adolescent psychiatric and personality disorder on long-term physical health: A 20year longitudinal follow-up study. Psychological Medicine, 39, 865-874.

Cicchetti, D., \& Rogosch, F.A. (2002). A developmental psychopathology perspective on adolescence. Journal of Consulting and Clinical Psychology, 70, 6-20.

Clarkin, J.F., Foelsch, P.A., Levy, K.N., Hull, J.W., Delaney, J.C., \& Kernberg, O.F. (2001). The development of a psychodynamic treatment for patients with borderline personality disorder: A preliminary study of behavioral change. Journal of Personality Disorders, 15, 487-495.

Cohen, P. (2008). Child development and personality disorder. Psychiatric Clinics of North America, 31, 477-493, vii.

Cohen, P., Chen, H., Gordon, K., Johnson, J., Brook, J., \& Kasen, S. (2008). Socioeconomic background and the developmental course of schizotypal and borderline personality disorder symptoms. Development and Psychopathology, 20, 633-650.

Cohen, P., Crawford, T.N., Johnson, J.G., \& Kasen, S. (2005). The Children in the Community Study of developmental course of personality disorder. Journal of Personality Disorders, 19, 466-486.

Coleman, J., \& Hendry, L.B. (1999). The nature of adolescence. London: Routledge.

Cooney, E., Davis, K., Thompson, P., Wharewera-Mika, J., Stewart, J., \& Miller, A.L. (2012). Feasibility of comparing dialectical behavior therapy with treatment as usual for suicidal and self-injuring adolescents: Follow-up data from a 
small randomized controlled trial. Paper presented at the Association of Behavioral and Cognitive Therapies 46th Annual Convention.

Cooney, E., Davis, K., Wharewera-Mika, J., \& Stewart, J. (2010). Feasibility of evaluating DBT for self-harming adolescents: A small randomised controlled trial. Auckland, New Zealand: National Centre of Mental Health Research, Information and Workforce Development.

Copeland, W.E., Shanahan, L., Costello, E.J., \& Angold, A. (2009). Childhood and adolescent psychiatric disorders as predictors of young adult disorders. Archives of General Psychiatry, 66, 764-772.

Crawford, T.N., Cohen, P.R., Chen, H., Anglin, D.M., \& Ehrensaft, M. (2009). Early maternal separation and the trajectory of borderline personality disorder symptoms. Development and Psychopatholpgy, 21, 1013-1030.

Crawford, T.N., Cohen, P., First, M.B., Skodol, A.E., Johnson, J.G., \& Kasen, S. (2008). Comorbid Axis I and Axis II disorders in early adolescence: Outcomes 20 years later. Archives of General Psychiatry, 65, 641-648.

Crick, N.R., Murray-Close, D., \& Woods, K. (2005). Borderline personality features in childhood: A short-term longitudinal study. Development and Psychopathology, 17, 1051-1070.

Crowell, S.E., Beauchaine, T.P., \& Linehan, M.M. (2009). A biosocial developmental model of borderline personality: Elaborating and extending Linehan's theory. Psychological Bulletin, 135, 495-510.

Crowell, S.E., Kaufman, E.A., \& Beauchaine, T.P. (2014). A biosocial model of BPD: Theory and empirical evidence. In C. Sharp \& J.L. Tackett (Eds.), Handbook of borderline personality disorder in children and adolescents (pp. 143157). New York: Springer.

Davies, P.T., Winter, M.A., \& Cicchetti, D. (2006). The implications of emotional security theory for understanding and treating childhood psychopathology. Development and Psychopathology, 18, 707-735.

De Clercq, B., De Fruyt, F., De Bolle, M., Van Hiel, A., Markon, K.E., \& Krueger, R.F. (2014). The hierarchical structure and construct validity of the PID-5 trait measure in adolescence. Journal of Personality, 82, 158-169.

De Clercq, B., De Fruyt, F., Van Leeuwen, K., \& Mervielde, I. (2006). The structure of maladaptive personality traits in childhood: A step toward an integrative developmental perspective for DSM-V. Journal of Abnormal Psychology, 115, 639-657.

De Clercq, B., Decuyper, M., \& De Caluwé, E. (2014). Developmental manifestations of borderline personality pathology from an age-specific dimensional personality disorder trait framework. In C. Sharp \& J.L. Tackett (Eds.), Handbook of borderline personality disorder in children and adolescents (pp. 81-94). New York: Springer.

De Clercq, B., van Leeuwen, K., van den Noortgate, W., de Bolle, M., \& de Fruyt, F. (2009). Childhood personality pathology: Dimensional stability and change. Development and Psychopathology, 21, 853-869.

Deutsch, H. (1942). Some forms of emotional disturbance and their relationship to schizophrenia. Psychoanalytic Quarterly, 11, 301-321.

Distel, M.A., Middeldorp, C.M., Trull, T.J., Derom, C.A., Willemsen, G., \& Boomsma, D.I. (2011). Life events and borderline personality features: The influence of geneenvironment interaction and gene-environment correlation. Psychological Medicine, 41, 849-860.

Distel, M.A., Trull, T.J., Derom, C.A., Thiery, E.W., Grimmer, M.A., Martin, N.G., .. . \& Boomsma, D.I. (2008). Heritability of borderline personality disorder features is similar across three countries. Psychological Medicine, 38, 1219-1229.

Dixon-Gordon, K.L., Chapman, A.L., Lovasz, N., \& Walters, K. (2011). Too upset to think: The interplay of borderline personality features, negative emotions, and social problem solving in the laboratory. Personality Disorders: Theory, Research, and Treatment, 2, 243-260.

Eaton, N.R., Krueger, R.F., Keyes, K.M., Skodol, A.E., Markon, K.E., Grant, B.F., \& Hasin, D.S. (2011). Borderline personality disorder co-morbidity: Relationship to the internalizing-externalizing structure of common mental disorders. Psychological Medicine, 41, 1041-1050.

Ellis, B.J., Del Giudice, M., Dishion, T.J., Figueredo, A.J., Gray, P., Griskevicius, V., .. \& \& Wilson, D.S. (2012). The evolutionary basis of risky adolescent behavior: Implications for science, policy, and practice. Developmental Psychology, 48, 598-623.

Escofet, P. (2012). Le microcosme juvénile: Sociabilité adolescente, école et violences. Gollion, Switzerland: Infolio.

Esposito-Smythers, C., Spirito, A., Kahler, C.W., Hunt, J., \& Monti, P. (2011). Treatment of co-occurring substance abuse and suicidality among adolescents: A randomized trial. Journal of Consulting and Clinical Psychology, 79, 728-739.

Fonagy, P., \& Luyten, P. (2009). A developmental, mentalization-based approach to the understanding and treatment of borderline personality disorder. Development and Psychopathology, 21, 1355-1381.

Fonagy, P., \& Luyten, P. (in press). A multilevel perspective on the development of borderline personality disorder. In D. Cicchetti (Ed.), Development and psychopathology (3rd edn). New York: John Wiley \& Sons.

Fonagy, P., Moran, G.S., \& Target, M. (1993). Aggression and the psychological self. International Journal of PsychoAnalysis, 74, 471-485.

Fonagy, P., Rossouw, T., Sharp, C., Bateman, A., Allison, L., \& Farrar, C. (2014). Mentalization-based treatment for adolescents with borderline traits. In C. Sharp \& J.L. Tackett (Eds.), Handbook of borderline personality disorder in children and adolescents (pp. 313-332). New York: Springer.

Fonagy, P., Target, M., \& Gergely, G. (2000). Attachment and borderline personality disorder. A theory and some evidence. Psychiatric Clinics of North America, 23, 103-122.

Fossati, A. (2014). Borderline personality disorder in adolescence: Phenomenology and construct validity. In C. Sharp \& J.L. Tackett (Eds.), Handbook of borderline personality disorder in children and adolescents (pp. 1934). New York: Springer.

Garner, B., Chanen, A.M., Phillips, L., Velakoulis, D., Wood, S.J., Jackson, H.J., . . \& McGorry, P.D. (2007). Pituitary volume in teenagers with first-presentation borderline personality disorder. Psychiatry Research, 156, 257-261.

Garnet, K.E., Levy, K.N., Mattanah, J.J., Edell, W.S., \& McGlashan, T.H. (1994). Borderline personality disorder in adolescents: Ubiquitous or specific? American Journal of Psychiatry, 151, 1380-1382.

Glenn, C.R., \& Klonsky, E.D. (2011). Prospective prediction of nonsuicidal self-injury: A 1-year longitudinal study in young adults. Behavior Therapy, 42, 751-762.

Goldstein, T.R., Axelson, D.A., Birmaher, B., \& Brent, D.A. (2007). Dialectical behavior therapy for adolescents with bipolar disorder: A 1-year open trial. Journal of the American Academy of Child and Adolescent Psychiatry, 46, 820-830.

Goodman, M., Hazlett, E.A., Avedon, J.B., Siever, D.R., Chu, K.W., \& New, A.S. (2011). Anterior cingulate volume reduction in adolescents with borderline personality disorder and co-morbid major depression. Journal of Psychiatric Research, 45, 803-807.

Goodman, M., Perez-Rodriguez, M., \& Siever, L. (2014). The neurobiology of adolescent-onset borderline personality disorder. In C. Sharp \& J.L. Tackett (Eds.), Handbook of borderline personality disorder in children and adolescents (pp. 113-128). New York: Springer.

Gordon, R.S., Jr (1983). An operational classification of disease prevention. Public Health Reports, 98, 107-109. 
Grant, B.F., Chou, S.P., Goldstein, R.B., Huang, B., Stinson, F.S., Saha, T.D., .. \& Ruan, W.J. (2008). Prevalence, correlates, disability, and comorbidity of DSM-IV borderline personality disorder: Results from the Wave 2 National Epidemiologic Survey on Alcohol and Related Conditions. Journal of Clinical Psychiatry, 69, 533-545.

Gratz, K.L., Tull, M.T., Reynolds, E.K., Bagge, C.L., Latzman, R.D., Daughters, S.B., \&Lejuez, C.W. (2009). Extending extant models of the pathogenesis of borderline personality disorder to childhood borderline personality symptoms: The roles of affective dysfunction, disinhibition, and self- and emotionregulation deficits. Development and Psychopathology, 21, 1263-1291.

Griffiths, M. (2011). Validity, utility and acceptability of borderline personality disorder diagnosis in childhood and adolescence: Survey of psychiatrists. The Psychiatrist, 35, 19-22.

Gunderson, J.G., \& Elliott, G.R. (1985). The interface between borderline personality disorder and affective disorder. American Journal of Psychiatry, 142, 277-288.

Gunderson, J.G., \& Lyons-Ruth, K. (2008). BPD's interpersonal hypersensitivity phenotype: A gene-environmentdevelopmental model. Journal of Personality Disorders, 22, $22-41$.

Gunderson, J.G., Stout, R.L., McGlashan, T.H., Shea, M.T., Morey, L.C., Grilo, C.M., .. \& Skodol, A.E. (2011). Ten-year course of borderline personality disorder: Psychopathology and function from the Collaborative Longitudinal Personality Disorders study. Archives of General Psychiatry, 68, 827-837.

Ha, C., Balderas, J.C., Zanarini, M.C., Oldham, J., \& Sharp, C. (2014). Psychiatric comorbidity in hospitalized adolescents with borderline personality disorder. Journal of Clinical Psychiatry, 75, e457-e464.

Hankin, B.L., Barrocas, A.L., Jenness, J., Oppenheimer, C.W., Badanes, L.S., Abela, J.R., ... \& Smolen, A. (2011). Association between 5-HTTLPR and borderline personality disorder traits among youth. Frontiers in Psychiatry, 2, 6.

Hare, T.A., Tottenham, N., Galvan, A., Voss, H.U., Glover, G.H., \& Casey, B.J. (2008). Biological substrates of emotional reactivity and regulation in adolescence during an emotional go-nogo task. Biological Psychiatry, 63, 927934.

Harvey, R., Blum, N., Black, D.W., Burgess, J., \& Henley-Cragg, P. (2014). Systems Training for Emotional Predictability and Problem Solving (STEPPS). In C. Sharp \& J.L. Tackett (Eds.), Handbook of child and adolescent borderline personality disorder (pp. 415-430). New York: Springer.

Hessels, C., van den Hanenberg, D., de Castro, B.O., \& van Aken, M.A. (2014). Relationships: Empirical contribution. Understanding personality pathology in adolescents: The five factor model of personality and social information processing. Journal of Personality Disorders, 28, 121-142.

Higgitt, A., \& Fonagy, P. (1992). Psychotherapy in borderline and narcissistic personality disorder. British Journal of Psychiatry, 161, 23-43.

Hoch, P., \& Polatin, P. (1949). Pseudoneurotic forms of schizophrenia. Psychiatric Quarterly, 23, 248-276.

James, L.M., \& Taylor, J. (2008). Revisiting the structure of mental disorders: Borderline personality disorder and the internalizing/externalizing spectra. British Journal of Clinical Psychology, 47, 361-380.

Jennings, T.C., Hulbert, C.A., Jackson, H.J., \& Chanen, A.M. (2012). Social perspective coordination in youth with borderline personality pathology. Journal of Personality Disorders, 26, 126-140.

Johnson, J.G., Cohen, P., Kasen, S., Skodol, A.E., \& Oldham, J.M. (2008). Cumulative prevalence of personality disorders between adolescence and adulthood. Acta Psychiatrica Scandinavica, 118, 410-413.

Jovev, M., Garner, B., Phillips, L., Velakoulis, D., Wood, S.J., Jackson, H.J., . . \& Chanen, A.M. (2008). An MRI study of pituitary volume and parasuicidal behavior in teenagers with first-presentation borderline personality disorder. Psychiatry Research, 162, 273-277.

Kaess, M., Hille, M., Parzer, P., Maser-Gluth, C., Resch, F., \& Brunner, R. (2012). Alterations in the neuroendocrinological stress response to acute psychosocial stress in adolescents engaging in nonsuicidal self-injury. Psychoneuroendocrinology, 37, 157-161.

Kaess, M., Parzer, P., Mattern, M., Plener, P.L., Bifulco, A., Resch, F., \& Brunner, R. (2013). Adverse childhood experiences and their impact on frequency, severity, and the individual function of nonsuicidal self-injury in youth. Psychiatry Research, 206, 265-272.

Kaess, M., von Ceumern-Lindenstjerna, I.A., Parzer, P., Chanen, A., Mundt, C., Resch, F., \& Brunner, R. (2013). Axis I and II comorbidity and psychosocial functioning in female adolescents with borderline personality disorder. Psychopathology, 46, 55-62.

Kendler, K.S., Myers, J., \& Reichborn-Kjennerud, T. (2011). Borderline personality disorder traits and their relationship with dimensions of normative personality: A web-based cohort and twin study. Acta Psychiatrica Scandinavica, 123, 349-359.

Kendler, K.S., Prescott, C.A., Myers, J., \& Neale, M.C. (2003). The structure of genetic and environmental risk factors for common psychiatric and substance use disorders in men and women. Archives of General Psychiatry, 60, 929-937.

Kernberg, P.F., Weiner, A.S., \& Bandenstein, K.K. (2000). Personality disorder in children and adolescents. New York: Basic Books.

Krueger, R.F., Derringer, J., Markon, K.E., Watson, D., \& Skodol, A.E. (2012). Initial construction of a maladaptive personality trait model and inventory for DSM-5. Psychological Medicine, 42, 1879-1890.

Laurenssen, E.M., Hutsebaut, J., Feenstra, D.J., Bales, D.L., Noom, M.J., Busschbach, J.J., .. \& L Luyten, P. (2014). Feasibility of mentalization-based treatment for adolescents with borderline symptoms: A pilot study. Psychotherapy, 51, $159-166$.

Laurenssen, E.M., Hutsebaut, J., Feenstra, D.J., Van Busschbach, J.J., \& Luyten, P. (2013). Diagnosis of personality disorders in adolescents: A study among psychologists. Child and Adolescent Psychiatry and Mental Health, 7, 3.

Leichsenring, F., Leibing, E., Kruse, J., New, A.S., \& Leweke, F. (2011). Borderline personality disorder. Lancet, 377, 74-84.

Lenzenweger, M.F. (2008). Epidemiology of personality disorders. Psychiatric Clinics of North America, 31, 395-403.

Lenzenweger, M.F., Lane, M.C., Loranger, A.W., \& Kessler, R.C. (2007). DSM-IV personality disorders in the National Comorbidity Survey Replication. Biological Psychiatry, 62, 553-564.

Lereya, S.T., Winsper, C., Heron, J., Lewis, G., Gunnell, D., Fisher, H.L., \& Wolke, D. (2013). Being bullied during childhood and the prospective pathways to self-harm in late adolescence. Journal of the American Academy of Child and Adolescent Psychiatry, 52, 608-618.

Leung, S.W., \& Leung, F. (2009). Construct validity and prevalence rate of borderline personality disorder among Chinese adolescents. Journal of Personality Disorders, 23, 494-513.

Levy, K.N., Becker, D.F., Grilo, C.M., Mattanah, J.J., Garnet, K.E., Quinlan, D.M., ... \& McGlashan, T.H. (1999). Concurrent and predictive validity of the personality disorder diagnosis in adolescent inpatients. American Journal of Psychiatry, 156, 1522-1528.

Lewinsohn, P.M., Rohde, P., Seeley, J.R., \& Klein, D.N. (1997). Axis II psychopathology as a function of Axis I disorders in childhood and adolescence. Journal of the American Academy of Child and Adolescent Psychiatry, 36, 17521759. 
Linehan, M.M. (1993). Cognitive-behavioral treatment of borderline personality disorder. New York: Guilford Press.

Luyten, P., \& Blatt, S.J. (2011). Integrating theory-driven and empirically-derived models of personality development and psychopathology: A proposal for DSM V. Clinical Psychology Review, 31, 52-68.

Lyons-Ruth, K. (2008). Contributions of the mother-infant relationship to dissociative, borderline, and conduct symptoms in young adulthood. Infant Mental Health Journal, 29, 203-218.

Macfie, J., \& Strimpfel, J.M. (2014). Parenting and the development of borderline personality disorder. In C. Sharp \& J.L. Tackett (Eds.), Handbook of borderline personality disorder in children and adolescents (pp. 277291). New York: Springer.

Macfie, J., \& Swan, S.A. (2009). Representations of the caregiver-child relationship and of the self, and emotion regulation in the narratives of young children whose mothers have borderline personality disorder. Development and Psychopathology, 21, 993-1011.

Maier-Hein, K.H., Brunner, R., Lutz, K., Henze, R., Parzer, P., Feigl, N., .. \& Stieltjes, B. (2014). Disorder-specific white matter alterations in adolescent borderline personality disorder. Biological Psychiatry, 75, 81-88.

Matusiewicz, A., Weaverling, G., \& Lejuez, C.W. (2014). Emotion dysregulation among adolescents with borderline personality disorder. In C. Sharp \& J.L. Tackett (Eds.), Handbook of borderline personality disorder in children and adolescents (pp. 177-194). New York: Springer.

McGlashan, T.H., Grilo, C.M., Skodol, A.E., Gunderson, J.G., Shea, M.T., Morey, L.C., .. \& Stout, R.L. (2000). The Collaborative Longitudinal Personality Disorders Study: Baseline Axis I/II and II/II diagnostic co-occurrence. Acta Psychiatrica Scandinavica, 102, 256-264.

McManus, M., Lerner, H., Robbins, D., \& Barbour, C. (1984). Assessment of borderline symptomatology in hospitalized adolescents. Journal of the American Academy of Child Psychiatry, 23, 685-694.

Meares, R., Gerull, F., Stevenson, J., \& Korner, A. (2011). Is self disturbance the core of borderline personality disorder? An outcome study of borderline personality factors. Australian and New Zealand Journal of Psychiatry, 45, 214-222.

Mehlum, L., Ramberg, M., Tørmoen, A., Haga, E., Larsson, B., \& Stanley, B., ... \& Grøholt, B. (2012). Dialectical behavior therapy for adolescents with recent and repeated suicidal and self-harm behavior: A randomized controlled trial. Paper presented at the Association of Behavioral and Cognitive Therapies 46th Annual Convention.

Mehlum, L., Tormoen, A.J., Ramberg, M., Haga, E., Diep, L.M., Laberg, S., ... \& Grøholt, B. (2014). Dialectical behavior therapy for adolescents with repeated suicidal and selfharming behavior: A randomized trial. Journal of the American Academy of Child and Adolescent Psychiatry, 53, 1082-1091.

Meijer, M., Goedhart, A.W., \& Treffers, P.D. (1998). The persistence of borderline personality disorder in adolescence. Journal of Personality Disorders, 12, 13-22.

Michonski, J.D. (2014). The underlying factor structure of DSM criteria in youth BPD. In C. Sharp \& J.L. Tackett (Eds.), Handbook of borderline personality disorder in children and adolescents (pp. 35-48). New York: Springer.

Michonski, J.D., Sharp, C., Steinberg, L., \& Zanarini, M.C. (2013a). An item response theory analysis of the DSM-IV borderline personality disorder criteria in a populationbased sample of 11- to 12-year-old children. Personality Disorders: Theory, Research, and Treatment, 4, 15-22.

Michonski, J.D., Sharp, C., Steinberg, L., \& Zanarini, M. (2013b). Borderline personality disorder criteria in a population-based sample of 11 to 12-year-old children: An item-level analysis. Houston, TX: University of Houston.
Miller, A.L., Carnesale, M.T., \& Courtney, E.A. (2014). Dialectical behavior therapy. In C. Sharp \& J.L. Tackett (Eds.), Handbook of borderline personality disorder in children in adolescents (pp. 385-401). New York: Springer.

Miller, A.L., Muehlenkamp, J.J., \& Jacobson, C.M. (2008). Fact or fiction: Diagnosing borderline personality disorder in adolescents. Clinical Psychology Review, 28, 969-981.

Monk, C.S., McClure, E.B., Nelson, E.E., Zarahn, E., Bilder, R.M., Leibenluft, E., ... \& Pine, D.S. (2003). Adolescent immaturity in attention-related brain engagement to emotional facial expressions. NeuroImage, 20, 420-428.

Moran, P., Coffey, C., Romaniuk, H., Olsson, C., Borschmann, R., Carlin, J.B., \& Patton, G.C. (2012). The natural history of self-harm from adolescence to young adulthood: A population-based cohort study. Lancet, 379, 236-243.

Morey, L.C. (2007). Personality Asssessment Inventory Adolescent professional manual. Odessa, FL: Psychological Assessment Resources.

Mrazek, P.J., \& Haggerty, R.J. (1994). Reducing risks for mental disorders. Washington, DC: National Academy Press.

National Health and Medical Research Council (2013). Clinical practice guideline for the management of borderline personality disorder 2012. Melbourne, Australia: Author.

National Institute for Health and Clinical Excellence. (2009).Borderline personality disorder: Treatment and management Clinical guideline Vol. 78. London: Author.

Nelson, E.E., Leibenluft, E., McClure, E.B., \& Pine, D.S. (2005). The social re-orientation of adolescence: A neuroscience perspective on the process and its relation to psychopathology. Psychological Medicine, 35, 163-174.

Ni, X., Bismil, R., Chan, K., Sicard, T., Bulgin, N., McMain, S., \& Kennedy, J.L. (2006). Serotonin 2A receptor gene is associated with personality traits, but not to disorder, in patients with borderline personality disorder. Neuroscience Letters, 408, 214-219.

Ni, X., Chan, D., Chan, K., McMain, S., \& Kennedy, J.L. (2009). Serotonin genes and gene-gene interactions in borderline personality disorder in a matched case-control study. Progress in Neuro-Psychopharmacology and Biological Psychiatry, 33, 128-133.

Ni, X., Sicard, T., Bulgin, N., Bismil, R., Chan, K., McMain, S., \& Kennedy, J.L. (2007). Monoamine oxidase A gene is associated with borderline personality disorder. Psychiatric Genetics, 17, 153-157.

Noblin, J.L., Venta, A., \& Sharp, C. (2013). The validity of the MSI-BPD among inpatient adolescents. Assessment, 21, 210-217.

Normandin, L., Ensink, K., Yeomans, F., \& Kernberg, O.F. (2014). Transference-focused psychotherapy for personality disorders in adolescence. In C. Sharp \& J.L. Tackett (Eds.), Handbook of child and adolesent borderline personality disorder (pp. 333-359). New York: Springer.

Oldham, J.M. (2006). Borderline personality disorder and suicidality. American Journal of Psychiatry, 163, 20-26.

Oldham, J.M., \& DeMasi, M.E. (1995). An integrated approach to emergency psychiatric care. New Directions for Mental Health Services, 33-42.

Paris, J. (1997). Antisocial and borderline personality disorders: Two separate diagnoses or two aspects of the same psychopathology? Comprehensive Psychiatry, 38, 237-242.

Paris, J. (2005). The development of impulsivity and suicidality in borderline personality disorder. Development and Psychopathology, 17, 1091-1104.

Paris, J. (2014). A history of research on borderline personality disorder in childhood and adolescence. In C. Sharp \& J.L. Tackett (Eds.), Handbook of borderline personality disorder in children and adolescents (pp. 9-17). New York: Springer.

Patton, G.C., Coffey, C., Romaniuk, H., Mackinnon, A., Carlin, J.B., Degenhardt, L., .. \& \& Moran, P., (2014). The prognosis 
of common mental disorders in adolescents: A 14-year prospective cohort study. Lancet, 383, 1404-1411.

Pietrek, C., Elbert, T., Weierstall, R., Muller, O., \& Rockstroh, B. (2013). Childhood adversities in relation to psychiatric disorders. Psychiatry Research, 206, 103-110.

Pinto, A., Grapentine, W.L., Francis, G., \& Picariello, C.M. (1996). Borderline personality disorder in adolescents: Affective and cognitive features. Journal of the American Academy of Child and Adolescent Psychiatry, 35, 13381343.

Poreh, A.M., Rawlings, D., Claridge, G., Freeman, J.L., Faulkner, C., \& Shelton, C. (2006). The BPQ: A scale for the assessment of borderline personality based on DSM-IV criteria. Journal of Personality Disorders, 20, 247-260.

Rathus, J.H., \& Miller, A.L. (2002). Dialectical behavior therapy adapted for suicidal adolescents. Suicide and LifeThreatening Behavior, 32, 146-157.

Reuter, T., Sharp, C., Temple, J., \& Babcock, J. (2015). An exploratory study of the relation between Borderline Personality Disorder features and teen dating violence in adolescence. Psychology of Violence: Advanced online publication.

Robins, E., \& Guze, S.B. (1970). Establishment of diagnostic validity in psychiatric illness: Its application to schizophrenia. American Journal of Psychiatry, 126, 983-987.

Rogosch, F.A., \& Cicchetti, D. (2005). Child maltreatment, attention networks, and potential precursors to borderline personality disorder. Development and Psychopathology, 17, 1071-1089.

Roisman, G.I., Masten, A.S., Coatsworth, J.D., \& Tellegen, A. (2004). Salient and emerging developmental tasks in the transition to adulthood. Child Development, 75, 123-133.

Rossouw, T.I., \& Fonagy, P. (2012). Mentalization-based treatment for self-harm in adolescents: A randomized controlled trial. Journal of the American Academy of Child and Adolescent Psychiatry, 51, 1304-1313 e1303.

Ryle, A., \& Kerr, I.B. (2002). Introducing cognitive analytic therapy: Principles and practice. Chichester, UK: John Wiley and Sons.

Sanislow, C.A., Morey, L.C., Grilo, C.M., Gunderson, J.G., Shea, M.T., Skodol, A.E., .. \& \& McGlashan, T.H. (2002). Confirmatory factor analysis of DSM-IV borderline, schizotypal, avoidant and obsessive-compulsive personality disorders: Findings from the Collaborative Longitudinal Personality Disorders Study. Acta Psychiatrica Scandinavica, 105, 28-36.

Schuppert, H.M., Giesen-Bloo, J., van Gemert, T.G., Wiersema, H.M., Minderaa, R.B., Emmelkamp, P.M., .. \& \& Nauta, M.H. (2009). Effectiveness of an emotion regulation group training for adolescents-a randomized controlled pilot study. Clinical Psychology and Psychotherapy, 16, 467-478.

Schuppert, H.M., Timmerman, M.E., Bloo, J., van Gemert, T.G., Wiersema, H.M., Minderaa, R.B., ... \& Nauta, M.H. (2012). Emotion regulation training for adolescents with borderline personality disorder traits: A randomized controlled trial. Journal of the American Academy of Child and Adolescent Psychiatry, 51, 1314-1323.

Selby, E.A., Kranzler, A., \& Panza, E. (2014). Development of emotional cascades in borderline personality disorder. In C. Sharp \& J.L. Tackett (Eds.), Handbook of borderline personality disorder in children and adolescents (pp. 159176). New York: Springer.

Shapiro, T. (1990). Resolved: Borderline personality exists in children under twelve. Negative. Journal of the American Academy of Child and Adolescent Psychiatry, 29, 480-482; discussion 482-483.

Sharp, C. (2014a). The social-cognitive basis of BPD: A theory of hypermentalizing. In C. Sharp \& J.L. Tackett (Eds.), Handbook of borderline personality disorder in children and adolescents (pp. 211-226). New York: Springer.
Sharp, C., (2014b). Locating BPD within the Internalizingexternalizing Spectrum in Adolescents. Paper presented at the annual meeting of the National Association for the Study of Personality Disorder, Boston, MA.

Sharp, C., \& Fonagy, P. (2008). Social cognition and attachmentrelated disorders. In C. Sharp, P. Fonagy \& I. Goodyer (Eds.), Social cognition and developmental psychopathology (pp. 269-302). Oxford, UK: Oxford University Press.

Sharp, C., Ha, C., Michonski, J., Venta, A., \& Carbone, C. (2012). Borderline personality disorder in adolescents: Evidence in support of the Childhood Interview for DSM-IV Borderline Personality Disorder in a sample of adolescent inpatients. Comprehensive Psychiatry, 53, 765-774.

Sharp, C., Mosko, O., Chang, B., \& Ha, C. (2011). The crossinformant concordance and concurrent validity of the Borderline Personality Features Scale for Children in a community sample of boys. Clinical Child Psychology and Psychiatry, 16, 335-349.

Sharp, C., \& Romero, C. (2007). Borderline personality disorder: A comparison between children and adults. Bulletin of the Menninger Clinic, 71, 85-114.

Sharp, C., Steinberg, L., Temple, J., \& Newlin, E. (2014). An 11-item measure to assess borderline traits in adolescents: Refinement of the BPFSC using IRT. Personality Disorders: Theory, Research, and Treatment, 5, 70-78.

Sharp, C., \& Tackett, J.L. (2014). Introduction: An idea whose time has come. In C. Sharp \& J.L. Tackett (Eds.), Handbook of borderline personality disorder in children and adolescents (pp. 3-8). New York: Springer.

Sharp, C., Wright, A.G., Fowler, J.C., Frueh, B.C., Allen, J.G., Oldham, J., \& Clark, L.A. (2015). The structure of personality pathology: Both general ('g') and specific ('s') factors? Journal of Abnormal Psychology, 124, 387-398.

Sheets, E., \& Craighead, W.E. (2007). Toward an empirically based classification of personality pathology. Clinical Psychology: Science and Practice, 14, 77-93.

Shiner, R.L. (2009). The development of personality disorders: Perspectives from normal personality development in childhood and adolescence. Development and Psychopathology, 21, 715-734.

Shiner, R.L., \& Caspi, A. (2012). Temperament and the development of personality traits, adaptations, and narratives. In M. Zentner \& R.L. Shiner (Eds.), Handbook of temperament (pp. 497-516). New York: Guilford Press.

Simeon, D., Bartz, J., Hamilton, H., Crystal, S., Braun, A., Ketay, S., \& Hollander, E. (2011). Oxytocin administration attenuates stress reactivity in borderline personality disorder: A pilot study. Psychoneuroendocrinology, 36, 1418-1421.

Skodol, A.E., Gunderson, J.G., Pfohl, B., Widiger, T.A., Livesley, W.J., \& Siever, L.J. (2002). The borderline diagnosis I: Psychopathology, comorbidity, and personality structure. Biological Psychiatry, 51, 936-950.

Skodol, A.E., Gunderson, J.G., Shea, M.T., McGlashan, T.H., Morey, L.C., Sanislow, C.A., .. \& \& Stout, R.L. (2005). The Collaborative Longitudinal Personality Disorders Study (CLPS): Overview and implications. Journal of Personality Disorders, 19, 487-504.

Speranza, M., Pham-Scottez, A., Revah-Levy, A., Barbe, R.P., Perez-Diaz, F., Birmaher, B., \& Corcos, M. (2012). Factor structure of borderline personality disorder symptomatology in adolescents. Canadian Journal of Psychiatry, 57, 230-237.

Speranza, M., Revah-Levy, A., Cortese, S., Falissard, B., PhamScottez, A., \& Corcos, M. (2011). ADHD in adolescents with borderline personality disorder. BMC Psychiatry, 11, 158.

Sperber, D., Clement, F., Heintz, C., Mascaro, O., Mercier, H., Origgi, G., \& Wilson, D. (2010). Epistemic vigilance. Mind \& Language, 25, 359-393.

Stanley, B., \& Siever, L.J. (2010). The interpersonal dimension of borderline personality disorder: Toward a neuropeptide model. American Journal of Psychiatry, 167, 24-39. 
Stepp, S.D., Burke, J.D., Hipwell, A.E., \& Loeber, R. (2012). Trajectories of attention deficit hyperactivity disorder and oppositional defiant disorder symptoms as precursors of borderline personality disorder symptoms in adolescent girls. Journal of Abnormal Child Psychology, 40, 7-20.

Stepp, S.D., Whalen, D.J., \& Pedersen, S.L. (2014). The externalizing pathway to borderline personality disorder in youth. In C. Sharp \& J.L. Tackett (Eds.), Handbook of borderline personality disorder in children and adolescents (pp. 247-264). New York: Springer.

Torgersen, S., Czajkowski, N., Jacobson, K., ReichbornKjennerud, T., Roysamb, E., Neale, M.C., \& Kendler, K.S. (2008). Dimensional representations of DSM-IV cluster B personality disorders in a population-based sample of Norwegian twins: A multivariate study. Psychological Medicine, 38, 1617-1625.

Torgersen, S., Lygren, S., Oien, P.A., Skre, I., Onstad, S., Edvardsen, J., ... \& Kringlen, E. (2000). A twin study of personality disorders. Comprehensive Psychiatry, 41, 416425.

Tyrer, P. (2014). The likely classification of borderline personality disorder in adolescents in ICD-11. In C. Sharp \& J.L. Tackett (Eds.), Handbook of borderline personality disorder in children and adolescents (pp. 451-458). New York: Springer.

Tyrer, P., Crawford, M., Mulder, R., Blashfield, R., Farnam, A., Fossati, A., .. \& Reed, G.M. (2011). The rationale for the reclassification of personality disorder in the 11 th revision of the International Classification of Diseases (ICD-11). Personality and Mental Health, 5, 246-259.

Walter, M., Bureau, J.F., Holmes, B.M., Bertha, E.A., Hollander, M., Wheelis, J., ... \& Lyons-Ruth, K. (2008). Cortisol response to interpersonal stress in young adults with borderline personality disorder: A pilot study. European Psychiatry, 23, 201-204.

Weiss, M., Zelkowitz, P., Feldman, R.B., Vogel, J., Heyman, M., $\&$ Paris, J. (1996). Psychopathology in offspring of mothers with borderline personality disorder: A pilot study. Canadian Journal of Psychiatry, 41, 285-290.

Westen, D., Betan, E., \& Defife, J.A. (2011). Identity disturbance in adolescence: Associations with borderline personality disorder. Development and Psychopathology, 23, 305-313.

Westen, D., Dutra, L., \& Shedler, J. (2005). Assessing adolescent personality pathology. British Journal of Psychiatry, 186, 227-238.

Whittle, S., Chanen, A.M., Fornito, A., McGorry, P.D., Pantelis, C., \& Yucel, M. (2009). Anterior cingulate volume in adolescents with first-presentation borderline personality disorder. Psychiatry Research, 172, 155-160.

Widiger, T.A., \& Trull, T.J. (1993). Borderline and narcissistic personality disorders, 2nd edn. New York: Plenum Press.

Wilcox, H.C., Arria, A.M., Caldeira, K.M., Vincent, K.B., Pinchevsky, G.M., \& O’Grady, K.E. (2012). Longitudinal predictors of past-year non-suicidal self-injury and motives among college students. Psychological Medicine, 42, 717-726.

Winograd, G., Cohen, P., \& Chen, H. (2008). Adolescent borderline symptoms in the community: Prognosis for functioning over 20 years. Journal of Child Psychology and Psychiatry, 49, 933-941.

Wolke, D., Schreier, A., Zanarini, M.C., \& Winsper, C. (2012). Bullied by peers in childhood and borderline personality symptoms at 11 years of age: A prospective study. Journal of Child Psychology and Psychiatry, 53, 846-855.

Yen, S., Weinstock, L.M., Andover, M.S., Sheets, E.S., Selby, E.A., \& Spirito, A. (2013). Prospective predictors of adolescent suicidality: 6-month post-hospitalization followup. Psychological Medicine, 43, 983-993.

Zaboli, G., Gizatullin, R., Nilsonne, A., Wilczek, A., Jonsson, E.G., Ahnemark, E., .. \& \& Leopardi, R. (2006). Tryptophan hydroxylase-1 gene variants associate with a group of suicidal borderline women. Neuropsychopharmacology, 31, 1982-1990.

Zanarini, M.C. (2003). The child interview for DSM-IV borderline personality disorder. Belmont, MA: McLean Hospital.

Zanarini, M.C., \& Frankenburg, F.R. (2007). The essential nature of borderline psychopathology. Journal of Personality Disorders, 21, 518-535.

Zanarini, M.C., Frankenburg, F.R., Dubo, E.D., Sickel, A.E., Trikha, A., Levin, A., \& Reynolds, V. (1998). Axis I comorbidity of borderline personality disorder. American Journal of Psychiatry, 155, 1733-1739.

Zanarini, M.C., Frankenburg, F.R., Hennen, J., Reich, D.B., \& Silk, K.R. (2006). Prediction of the 10-year course of borderline personality disorder. American Journal of Psychiatry, 163, 827-832.

Zanarini, M.C., Frankenburg, F.R., Khera, G.S., \& Bleichmar, J. (2001). Treatment histories of borderline inpatients. Comprehensive Psychiatry, 42, 144-150.

Zanarini, M.C., Frankenburg, F.R., Reich, D.B., \& Fitzmaurice, G. (2012). Attainment and stability of sustained symptomatic remission and recovery among patients with borderline personality disorder and axis II comparison subjects: A 16-year prospective follow-up study. American Journal of Psychiatry, 169, 476-483.

Zanarini, M.C., Horwood, J., Wolke, D., Waylen, A., Fitzmaurice, G., \& Grant, B.F. (2011). Prevalence of DSMIV borderline personality disorder in two community samples: 6,330 English 11-year-olds and 34,653 American adults. Journal of Personality Disorders, 25, 607-619.

Zanarini, M.C., Vujanovic, A.A., Parachini, E.A., Boulanger, J.L., Frankenburg, F.R., \& Hennen, J. (2003). A screening measure for BPD: The McLean screening instrument for borderline personality disorder (MSI-BPD). Journal of Personality Disorders, 17, 568-573.

Zanarini, M., \& Wedig, M. (2014). Childhood adversity and the development of borderline personality disorder. In C. Sharp \& J.L. Tackett (Eds.), Handbook of borderline personality disorder in children and adolescents (pp. 265-276). New York: Springer.

Zimmerman, M., \& Mattia, J.I. (1999). Axis I diagnostic comorbidity and borderline personality disorder. Comprehensive Psychiatry, 40, 245-252.

Accepted for publication: 11 June 2015 